\title{
GESTIÓN ADECUADA Y APLICACIÓN DE LAS TECNOLOGÍAS EN EL SISTEMA DE JUSTICIA CIVIL ${ }^{1}$
}

\section{ADEQUATE MANAGEMENT AND APPLICATION OF TECHNOLOGIES \\ IN THE CIVIL JUSTICE SYSTEM}

Santiago Pereira Campos Profesor Titular de Derecho Procesal y Director del Postgrado en Derecho Procesal Aplicado y de la Maestría en Derecho con Énfasis en Derecho Procesal en la Facultad de Derecho de la Universidad de Montevideo. Miembro del Consejo Directivo del Instituto Iberoamericano de Derecho Procesal. Facilitador de la Comisión de expertos para la Reforma Procesal Civil y Comercial del Ministerio de Justicia y Derechos Humanos de la Nación (Argentina - Justicia 2020). Ex Presidente del Consejo Directivo del Centro de Estudios de Justicia de las Américas (CEJA-OEA). Miembro de la Asociación Internacional de Derecho Procesal y Fundador de la Asociación Uruguaya de Derecho Procesal "Eduardo J. Couture". Socio de RUEDA ABADI PEREIRA. Profesor del Diplomado sobre Reforma Procesal Civil de la Pontificia Universidad Católica de Chile. Ha sido consultor de PNUD, ONUDI, BID, FOMIN, CEJA y del Instituto del BANCO MUNDIAL. Las opiniones del autor son formuladas a título personal y no comprometen a las instituciones que integra. Montevideo, Uruguay. E-mail: spereira@rap.com.uy. Twitter: @ SantiagoPCampos

\footnotetext{
${ }^{1}$ Artigo recebido em 08/08/2019, sob dispensa de revisão.
} 
RESUMEN: El artículo aborda los desafíos de implementar un modelo de gestión adecuado, con la aplicación de tecnología, buscando la eficiencia de la justicia civil. A partir de los desafíos, busca retratar cómo fue posible construir algunas experiencias exitosas.

PALABRAS-CLAVE: Gestión adecuada; tecnologías; Justicia Civil.

ABSTRACT: This paper deals with the challenges of implementing an adequate management model, with the application of technology, seeking the efficiency of civil justice. Based on the challenges, he seeks to portray how it was possible to build some successful experiences.

KEY WORDS: Adequate management; technologies; Civil Justice.

SUMÁRIO: 1 . Gestión y tecnologías en el marco de un plan sistémico de justicia civil con enfoque de política pública. 2.El Diseño De La Gestión Eficiente Del Sistema De Justicia Civil. 2.1. Los desafíos de un modelo de gestión adecuado. 2.2. Contenidos del modelo de gestión. 2.3. Algunas experiencias innovadoras. 3. Las tecnologías de información y comunicación (tic's) en el sistema de justicia civil.

\section{GESTIÓN Y TECNOLOGÍAS EN EL MARCO DE UN PLAN SISTÉMICO DE JUSTICIA CIVIL CON ENFOQUE DE POLÍTICA PÚBLICA}

Todo estudio y generación de propuestas en relación al sistema de justicia civil, debe tener un enfoque sistémico, multidisciplinario e integral con perspectiva de política pública. Debe definir las variadas formas de soluciones posibles desde el Estado, articulando las diversas herramientas de prevención y resolución de conflictos. 
Revista Eletrônica de Direito Processual - REDP.

Rio de Janeiro. Ano 13. Volume 20. Número 3. Setembro a Dezembro de 2019

Periódico Quadrimestral da Pós-Graduação Stricto Sensu em Direito Processual da UERJ

Patrono: José Carlos Barbosa Moreira (in mem.). ISSN 1982-7636. pp. 483-523

www.redp.uerj.br

Por ende, para considerar la gestión y tecnologías en el sistema de justicia, debe también partirse de este enfoque ${ }^{2}$.

Existe evidencia empírica de que los procesos de reforma y modernización de la Justicia Civil que han sido diseñados e implementados con carencias en esa visión sistémica de política pública, han tenido muchos problemas de implementación ${ }^{3}$ e incluso, en muchos casos minaron las bases del cambio de paradigma necesario.

Señala $\mathrm{LILLO}^{4}$ que en la región si bien se ha dado un proceso de discusión y cambio normativo intenso y profundo, los procesos de implementación de las normas, los cambios culturales o las prácticas de los actores y el conocimiento, participación y confianza de la ciudadanía respecto de estos han sido más bien débiles y escasos de planificación. Esto ha derivado a una rediscusión de los procesos de reforma, para focalizar los esfuerzos en las prácticas más que en la norma. Con ello, se han abierto nuevos ámbitos de reflexión y trabajo orientados principalmente a temas de organización y gestión institucional. Detectado este problema, se han desarrollado muchas acciones tendientes a mejorar la implementación de las reformas: desde readecuaciones organizativas, nuevas formas de trabajo y la incorporación de herramientas tecnológicas.

En efecto, no siempre acompañado por adecuados esfuerzos estatales, se percibe especialmente en los últimos años un cambio de enfoque de los diseñadores de las reformas, en cuanto a entender que se requieren visiones integrales y multidisciplinarias, con adecuados diagnósticos, diseños ajustados a la realidad, y seguimiento permanente de los resultados.

\footnotetext{
${ }^{2}$ Algunas partes del presente trabajo tiene su fuente en el documento que preparáramos para CEJA hace unos años atrás, ahora actualizado con nueva información y nuevos contenidos: PEREIRA CAMPOS, Santiago; VILLADIEGO, Carolina y CHAYER, Héctor, “Bases Generales para una Reforma a la Justicia Civile en América Latina y el Caribe”, publicado en PEREIRA CAMPOS, S. (Coordinador) y otros, “Modernización de la Justicia Civil", Universidad de Montevideo, 2011 y en otras partes se ha recurrido a las recientes investigaciones y estudios de CEJA disponibles en la biblioteca virtual de cejamericas.org

${ }^{3}$ Ejemplos pueden encontrarse en las reformas procesales civiles de Perú, El Salvador, Nicaragua, Bolivia, o en la primera fase de la implementación de la reforma del sistema de justicia de familia de Chile.

${ }^{4}$ LILLO, Ricardo, "Indicadores de CEJA: El rol de las TIC en una justicia para ciudadanos", Revista Sistema Judiciales, CEJA. Año 9, No 16, p. 6.
} 
Revista Eletrônica de Direito Processual - REDP.

Rio de Janeiro. Ano 13. Volume 20. Número 3. Setembro a Dezembro de 2019

Periódico Quadrimestral da Pós-Graduação Stricto Sensu em Direito Processual da UERJ

Patrono: José Carlos Barbosa Moreira (in mem.). ISSN 1982-7636. pp. 483-523

www.redp.uerj.br

Un plan sistémico e integral para el mejoramiento permanente de un sistema de justicia civil, debe $^{5}$ :

- Contar con una metodología que permita el diseño e implementación de los cambios, que garantice la efectiva incorporación de los elementos centrales al sistema y, en caso de ya estar incorporados, someter los mismos a evaluación permanente para introducir los ajustes necesarios.

- Realizar sistematicos relevamientos de la situación, de modo de obtener información fiable que permita un adecuado funcionamiento del sistema. Como se ha señalado desde el CEJA ${ }^{6}$ :

"Cualquier reforma al proceso civil debe partir por un diagnóstico de la conflictividad para, a continuación, profundizar en cómo diseñaremos las diversas modalidades de solución de conflictos judiciales y no judiciales. Este proceso de diagnóstico y diseño de la reforma al sistema de justicia civil debe realizarse con la participación directa de representantes de la sociedad civil y de los sectores interesados en la solución de los conflictos civiles. Finalmente, es fundamental realizar un trabajo de seguimiento y evaluación de la reforma, que permita la rendición de cuentas con la ciudadanía así como también realizar ajustes sobre el diseño originalmente previsto".

- Contar con un plan de diseño para introducir de modo integral y sistemático los cambios necesarios, propendiendo a la participación ciudadana.

- Definir los mecanismos requeridos para la implementación adecuada de las reformas necesarias, considerando las necesidades ciudadanas.

- Diseñar una transformación normativa que incorpore las herramientas legales necesarias para la implementación de los cambios requeridos.

\footnotetext{
${ }^{5} \mathrm{Al}$ respecto hemos escrito anteriormente en PEREIRA CAMPOS, S., "Hacia un nuevo sistema de Justicia Civil", en ESPERANZA Silvia (coordinadora) y otros, "Derecho Procesal Civil y Comercial - Estudios en homenaje al Dr. Jorge W. Peyrano", Rubinzal-Culzoni Editores, Buenos Aires, 2018, ps.749 y ss.

${ }^{6}$ CEJA, "10 Ideas sobre el modelo de reforma a la justicia civil que promueve CEJA en América Latina y el Caribe".

http://www.cejamericas.org/Documentos/2018/10_IdeassobreelmodelodereformaalajusticiacivilquepromueveCEJ AenAmericaLatinayelCaribe_coninfografias.pdf
} 
Revista Eletrônica de Direito Processual - REDP.

Rio de Janeiro. Ano 13. Volume 20. Número 3. Setembro a Dezembro de 2019

Periódico Quadrimestral da Pós-Graduação Stricto Sensu em Direito Processual da UERJ

Patrono: José Carlos Barbosa Moreira (in mem.). ISSN 1982-7636. pp. 483-523

www.redp.uerj.br

- Capacitar para el cambio cultural que implica la nueva forma de litigación oral. Como se ha señalado desde el CEJA ${ }^{7}$ :

"Un primer desafío con la oralidad tiene que ver con entender este principio como una metodología para el intercambio de información de alta calidad entre las partes y el juez/a. Por lo tanto, el mero hecho de emplear el lenguaje oral no quiere decir que el principio de oralidad funcione de forma adecuada. Por ejemplo, la "teatralización del expediente" en la que los/as abogados/as leen de forma íntegra sus escritos postulatorios no genera información de alta calidad. Por otro lado, para que podamos alcanzar este funcionamiento oral adecuado, es fundamental que exista un trabajo profundo en las destrezas de litigación oral necesarias. Para ello, los/as operadores/as del sistema deben haber sido capacitados/as sobre teoría del caso, admisibilidad probatoria, técnicas de examen y contraexamen, entre otros temas. Esta capacitación se debe realizar en base a simulaciones prácticas y no en base a la memorización de la normativa. Solamente con este trabajo de capacitación avanzada se logrará que el principio de contradicción de la prueba logre su objetivo final de generar información de alta calidad en el proceso de valoración de la prueba que realiza la autoridad judicial".

Aquí resulta clave el rol de las Universidades y Escuelas Judiciales.

- Diseñar la adecuación organizacional necesaria para que los distintos operadores del sistema de justicia civil puedan implementar los cambios establecidos.

- $\quad$ Establecer herramientas apropiadas para la adopción de los cambios por los distintos actores del sistema de justicia con metas e indicadores claros y eficientes.

- Promover la perspectiva de género en el sistema de justicia mediante la definición de una política de igualdad de género y un plan de acción para implementarla.

- Definir criterios para establecer reglas de lenguaje claro en el sistema de justicia.

- Definir los mecanismos de implementación de los cambios que se van resolviendo.

- Apropiar los recursos requeridos para la implementación (gradual o inmediata) de los cambios.

- $\quad$ Establecer procedimientos de monitoreo y evaluación sistémicos.

\footnotetext{
${ }^{7}$ CEJA, "10 Ideas sobre el modelo de reforma a la justicia civil que promueve CEJA en América Latina y el Caribe".

http://www.cejamericas.org/Documentos/2018/10_IdeassobreelmodelodereformaalajusticiacivilquepromueveCEJ AenAmericaLatinayelCaribe_coninfografias.pdf
} 
Revista Eletrônica de Direito Processual - REDP.

Rio de Janeiro. Ano 13. Volume 20. Número 3. Setembro a Dezembro de 2019

Periódico Quadrimestral da Pós-Graduação Stricto Sensu em Direito Processual da UERJ

Patrono: José Carlos Barbosa Moreira (in mem.). ISSN 1982-7636. pp. 483-523

www.redp.uerj.br

- Establecer mecanismos apropiados para realizar los ajustes requeridos en el proceso de

implementación de las reformas, considerando las metas y los indicadores predefinidos.

- Generar ámbitos de diálogo entre actores claves de la justicia civil, incluidos los operadores del sistema y los usuarios potenciales y permanentes.

Señala OTEIZA ${ }^{8}$ que

"al desarrollar un proceso de reforma los Estados enfrentan opciones sobre cómo desactivar las barreras que limitan el acceso a la justicia teniendo en cuenta la vulnerabilidad de diversos sectores sociales, establecer mecanismos que resulten aceptables para asegurar la independencia al seleccionar y, en su caso, responsabilizar a los jueces, constituir tribunales de acuerdo con una determinada carga de trabajo y cercanos territorialmente con los usuarios del servicio, fijar reglas sobre recusaciones y excusaciones como garantía de imparcialidad, brindar poderes al órgano judicial para la conducción de los casos a decidir y para fijar una agenda que permita llevar adelante los pasos que requiere una efectiva contradicción, lograr la inmediación del juez con las partes y una cuota de oralidad adecuada, contar con aceptables estructuras burocráticas, edilicias y tecnológicas encargadas de dar soporte a la actividad judicial, dotar de transparencia al servicio, regular acertadamente la amplitud del debate en cada uno de los tipos de procesos, diferenciando conflictos y regulando vías diversas según la materia a tratar, brindar un espacio para que las partes acuerden una solución amistosa, reducir la duración de los juicios, acertar sobre el grado de formalidad exigida, regular las impugnaciones desalentando las que resulten innecesarias, sin lesionar el derecho a una razonable revisión, dotar al ordenamiento de mecanismos eficientes para ejecutar las decisiones, establecer incentivos y desincentivos para mejorar el acceso, reducir gastos innecesarios, exigir que los pronunciamientos exhiban aceptables niveles de fundamentación y establecer pautas para darle tanto previsibilidad como flexibilidad a la jurisprudencia de los tribunales. Esas metas o dilemas de política pública constituyen parte del difícil entramado de dilemas que los Estados deben decidir al dar forma a un proyecto sobre la justicia civil".

\footnotetext{
${ }^{8}$ OTEIZA, Eduardo, "Reformas procesales en América Latina. Tendencias y tensiones entre los Estados Nación y la Comunidad Internacional" en OTEIZA, Eduardo (coordinador) y otros, "Sendas de la reforma de la justicia a principios del siglo XXI", Marcial Pons, Madrid, 2018, ps. 49 y 50.
} 
Revista Eletrônica de Direito Processual - REDP.

Rio de Janeiro. Ano 13. Volume 20. Número 3. Setembro a Dezembro de 2019

Periódico Quadrimestral da Pós-Graduação Stricto Sensu em Direito Processual da UERJ

Patrono: José Carlos Barbosa Moreira (in mem.). ISSN 1982-7636. pp. 483-523

www.redp.uerj.br

La modernización de la Justicia Civil no puede omitir el análisis de la organización judicial con la que cuenta el país (tribunales, competencias, sistema de ascensos y carrera judicial, etc.), y los recursos humanos y materiales existentes (jueces, funcionarios, oficinas, equipamiento, tecnología, etc.) para operativizar cualquier cambio.

En este proceso, el Gobierno Judicial resulta clave ${ }^{9}$. Como señala ARELLANO $^{10}$, el gobierno judicial es tema esencial para la consolidación de las democracias latinoamericanas. Definir conceptualmente y conocer empíricamente lo que es y cómo funciona el Poder Judicial de los Estados es tarea fundamental para poder garantizar no solamente la legitimidad de los jueces y juezas en el desempeño de sus competencias, sino, más importante, asegurar la impartición justa de los derechos ciudadanos. Agrega:

"La discusión sobre el gobierno judicial debe incluir una dimensión política, que trate de la independencia del Poder Judicial frente a otros poderes públicos y grupos de interés particulares, y, además, debe considerar la dimensión operativa de organización y actuación de los magistrados y magistradas, desde el punto de vista del fortalecimiento de su autonomía funcional, y de la transparencia y objetividad de las reglas referentes a la selección, nombramiento y ascenso en la carrera".

Señala BINDER ${ }^{11}$ que los sistemas de justicia de América Latina suele presentar debilidad institucional de los gobiernos judiciales, atrapados en instituciones y organizaciones de conducción obsoletas y que

"no fueron pensadas para un verdadero ejercicio independiente del poder de los jueces y para la defensa de esa independencia para el recio juego de intereses, propio de la democracia moderna. Quedo claro,

\footnotetext{
${ }^{9}$ Los principales modelos de Gobierno Judicial en los poderes judiciales de América Latina son: a) supremas cortes o cortes supremas con un rol protagónico en el gobierno y administración del Poder Judicial (Uruguay, Chile, Guatemala); Consejos de la Magistratura o Judicatura (Ecuador, Colombia, Argentina); y sistemas de repartición de responsabilidades entre la Corte Suprema y el Consejo de la Magistratura (Paraguay).

10 ARELLANO, Jaime, "Presentación", en BINDER, Alberto y GONZÁLEZ, Leonel (Directores) y otros, "Gobierno Judicial. Independencia y fortalecimiento del Poder Judicial en América Latina", CEJA, Santiago de Chile, $\mathrm{p} 7$.

${ }^{11}$ BINDER, Alberto, "Gobierno judicial. Independencia y fortalecimiento de los jueces", en BINDER, Alberto y GONZÁLEZ, Leonel (Directores) y otros, Ob. Cit., p 16.
} 
Revista Eletrônica de Direito Processual - REDP.

Rio de Janeiro. Ano 13. Volume 20. Número 3. Setembro a Dezembro de 2019

Periódico Quadrimestral da Pós-Graduação Stricto Sensu em Direito Processual da UERJ

Patrono: José Carlos Barbosa Moreira (in mem.). ISSN 1982-7636. pp. 483-523

www.redp.uerj.br

entonces, que un solo juez aislado, por más que tuviera una gran capacidad profesional y un compromiso cívico excepcional, no podía, por sí solo, resolver el conjunto de tensiones que se acumulaban en el espacio de la justicia, pensado como un campo institucional con reglas, actores y racionalidades específicas".

Por otra parte, la modernización del modelo procesal debe contemplar los principios $\mathbf{y}$ las nuevas estructuras procesales adecuadas para la satisfacción de los derechos sustanciales. El proceso ordinario por audiencias y el proceso monitorio son las estructuras más atractivas por eficiencia y adecuación a los principios procesales que la doctrina identifica como claves, coordinados con un sistema de justicia de cercanía y/o pequeñas causas o vecinal sencillo y accesible y una adecuada solución para los procesos colectivos.

Deben buscarse soluciones innovadoras al "drama" del proceso de ejecución que azota nuestros países (obtener una sentencia es lento, ejecutarla es casi imposible). Es este sentido existen experiencias interesantes a adaptar a nuestros países en sistemas europeos (Alemania, España, Gran Bretaña, etc.)

A partir de estos elementos, debe plantearse la nueva organización y gestión de los despachos judiciales, asumiendo los cambios organizacionales y procesales, y los recursos que ellos demanden, con el auxilio de las nuevas tecnologías.

Un adecuado plan de capacitación previo, concomitante y permanente con todos los operadores jurídicos y de los ciudadanos en general permite realizar el paso de la realidad anterior al nuevo modelo de justicia.

La satisfacción plena de los estándares del debido proceso ajustados al derecho material en juego en cada caso, no será posible sin la visión de que el proceso es solo uno de los mecanismos de solución de conflictos pero que deben considerarse todos los instrumentos en la búsqueda del medio adecuado de resolución del conflicto. Son fundamentales, en este enfoque, aquellos medios que proveen simultáneamente soluciones rápidas y auto compuestas de estricta calidad. Como se indica en los estudios del Centro de Estudios de Justicia de las Américas (CEJA) 12: "Una reforma que no establezca claramente cómo se va a coordinar la

\footnotetext{
${ }^{12}$ CEJA, "10 Ideas sobre el modelo de reforma a la justicia civil que promueve CEJA en América Latina y el Caribe”
} 
Revista Eletrônica de Direito Processual - REDP.

Rio de Janeiro. Ano 13. Volume 20. Número 3. Setembro a Dezembro de 2019

Periódico Quadrimestral da Pós-Graduação Stricto Sensu em Direito Processual da UERJ

Patrono: José Carlos Barbosa Moreira (in mem.). ISSN 1982-7636. pp. 483-523

www.redp.uerj.br

justicia civil con los MASC extrajudiciales (mediación/conciliación previa voluntaria $u$ obligatoria) o intrajudiciales (conciliación intraprocesal o mediación judicial) está llamada a fracasar".

Por otro lado, es fundamental articular el sistema con las modalidades de solución de conflictos de carácter comunitario y originario que no siempre son tenidas en cuenta en los procesos de reforma ${ }^{13}$.

Finalmente, la justicia civil modernizada debe contar con sistemas adecuados de asistencia jurídica a los ciudadanos, que garanticen una igualdad procesal efectiva.

\section{EL DISEÑO DE LA GESTIÓN EFICIENTE DEL SISTEMA DE JUSTICIA CIVIL}

\subsection{Los desafíos de un modelo de gestión adecuado}

Los desafíos y los riesgos en los procesos de mejora de los sistemas de justicia no terminan ni empiezan en aspectos de Derecho Procesal. Por el contrario, el enfoque sistémico e integral de los procesos de reforma, requiere considerar con especial cuidado el modo de diseñar la gestión de los tribunales, buscando separar las funciones jurisdiccionales de las administrativas y propendiendo a que el Juez se concentre en las primeras, delegando en expertos en gestión y administración las segundas. Ello entraña algunos riesgos de implementación pero los resultados suelen ser a la larga exitosos.

Hemos dicho años atrás con CHAYER y VILLADIEGO ${ }^{14}$, que un adecuado modelo de gestión de la justicia civil debe ser particularmente eficaz y eficiente en el uso de los escasos recursos públicos. Los fondos públicos destinados a la justicia tienen la obligación de ser aplicados con eficacia y eficiencia pues está comprometido el interés público. Existen numerosas alternativas para su aplicación (educación primaria, atención de la salud,

\footnotetext{
http://www.cejamericas.org/Documentos/2018/10_IdeassobreelmodelodereformaalajusticiacivilquepromueveCEJ AenAmericaLatinayelCaribe_coninfografias.pdf

${ }^{13}$ CEJA, "10 Ideas sobre el modelo de reforma a la justicia civil que promueve CEJA en América Latina y el Caribe"

http://www.cejamericas.org/Documentos/2018/10_IdeassobreelmodelodereformaalajusticiacivilquepromueveCEJ AenAmericaLatinayelCaribe_coninfografias.pdf

${ }^{14}$ PEREIRA CAMPOS, Santiago; VILLADIEGO, Carolina y CHAYER, Héctor, Ob. cit., p. 107.
} 
Revista Eletrônica de Direito Processual - REDP.

Rio de Janeiro. Ano 13. Volume 20. Número 3. Setembro a Dezembro de 2019

Periódico Quadrimestral da Pós-Graduação Stricto Sensu em Direito Processual da UERJ

Patrono: José Carlos Barbosa Moreira (in mem.). ISSN 1982-7636. pp. 483-523

www.redp.uerj.br

infraestructura, entre otras) que compiten en la apropiación de recursos en la agenda pública.

Considerar que los recursos que se asignan al sector justicia no deben guiarse por estos principios es inaceptable, pues justifica el gasto regresivo e injusto.

FANDIÑO ${ }^{15}$ define la gestión judicial como "un área de conocimiento multidisciplinario relacionada con el funcionamiento eficiente de los juzgados y tribunales y que comprende tanto la administración de los recursos administrativos como de los recursos jurisdiccionales".

Señalamos con CHAYER y VILLADIEGO ${ }^{16}$ que la justicia civil ha tenido tradicionalmente un modelo de gestión poco eficiente que responde a la idea de despacho judicial como nicho independiente y autónomo, calificado repetidamente como "insular". Este modelo se funda en una errada comprensión del concepto de independencia judicial y de la confusión entre funciones administrativas y jurisdiccionales.

Señala FANDIÑO ${ }^{17}$, citando a VARGAS que el modelo de organización de los juzgados que ha tenido mayor presencia en los últimos dos siglos en América Latina, se puede definir como colonial-piramidal. Indica: "Se trata de un modelo colonial ya que tiene su origen en el proceso colonizador español y portugués en el territorio latinoamericano y se considera piramidal por la forma en que se distribuyen los recursos humanos". En la cúspide de esta pirámide se encuentra siempre la autoridad judicial, quien se desempeña como superior jerárquico en todas las funciones jurisdiccionales y administrativas que se lleven a cabo en el tribunal $^{18}$. En este modelo, el/la juez/a tiene la última palabra sobre todo lo que pase en su juzgado. Un rasgo característico de este modelo es la existencia de un/a secretario/a judicial en los juzgados o tribunales. Finalmente, la organización tradicional de los juzgados culmina con un grupo de empleados/as administrativos para apoyar en determinadas funciones en las que sean requeridos tanto en el ámbito jurisdiccional como administrativo, siendo una de sus grandes preocupaciones la conservación del expediente como fuente de información principal del

\footnotetext{
${ }^{15}$ FANDIÑO, M., "Lineamientos para la transformación de los juzgados civiles en base a los nuevos paradigmas procesales" en "La gestión judicial de los nuevos tribunales civiles", CEJA, 2018, p 20.

${ }^{16}$ PEREIRA CAMPOS, Santiago; VILLADIEGO, Carolina y CHAYER, Héctor, Ob. cit., p. 107.

${ }^{17}$ FANDIÑO, M., Ob. cit., ps. 13 y 14.

${ }^{18}$ Como señala FANDIÑO, en algunos países de la región, todavía es el/la juez/a quien contrata a su propio personal, autoriza sus vacaciones o realiza gestiones para conseguir más papel o tinta para las impresoras (FANDIÑO, M., Ob. Cit., ps. 13 y 14).
} 
Revista Eletrônica de Direito Processual - REDP.

Rio de Janeiro. Ano 13. Volume 20. Número 3. Setembro a Dezembro de 2019

Periódico Quadrimestral da Pós-Graduação Stricto Sensu em Direito Processual da UERJ

Patrono: José Carlos Barbosa Moreira (in mem.). ISSN 1982-7636. pp. 483-523

www.redp.uerj.br

proceso que deben custodiar. Otra característica de este modelo de funcionamiento es que los juzgados, a la hora de ejercer su función jurisdiccional, atienden a los criterios de competencia, habitualmente distinguiéndose entre la competencia objetiva, funcional y territorial.

Indica con razón el autor citado, que la capacidad de persistencia de esta forma de organizar los tribunales no es antojadiza sino que -por el contrario- responde a importantes razones de carácter histórico, político y, en algunos casos, también simbólico. La tramitación de procedimientos de forma escrita, conlleva la inevitable instalación de la cultura del trámite y del incidente.

Por ende, frente a ese panorama, como señala $\mathrm{BINDER}^{19}$, es necesario modernizar el modo de trabajo y las organizaciones de trabajo del Poder Judicial, para que la publicidad, la oralidad y la adecuada gerencia de recursos humanos y materiales permita que el entorno institucional y laboral del juez facilitara su independencia. La gestión tiene relación directa con la independencia judicial.

BINDER $^{20}$ pone de relieve la fuerte carga de expectativas políticas sobre el Poder Judicial, que se expresa en las Constituciones de nuestros países. Esta carga opera no sólo respecto de la función esencial de la jurisdicción, que es fortalecer la vigencia de la ley común, sino a través de las nuevas formas de control de constitucionalidad -y su enorme capacidad para configurar la totalidad del sistema normativo- y una difusa expectativa en el sentido de control de los excesos del poder público.

El primer problema deriva entonces de entender el principio de independencia judicial como un privilegio de los jueces, en vez de considerarlo una garantía ciudadana.

Además, deviene de haber extendido sin contextualización adecuada la independencia judicial al campo de la gestión de los tribunales, donde lo que debe propenderse es a la transparencia de gestión.

El segundo problema, proviene de la confusión entre funciones administrativas y jurisdiccionales que conspira contra la eficacia y eficiencia del sistema de justicia, y permite la delegación indebida de funciones jurisdiccionales.

\footnotetext{
${ }^{19}$ BINDER, Alberto, Ob. Cit., p. 12.

${ }^{20}$ BINDER, Alberto, Ob. Cit., p. 12.
} 
Revista Eletrônica de Direito Processual - REDP.

Rio de Janeiro. Ano 13. Volume 20. Número 3. Setembro a Dezembro de 2019

Periódico Quadrimestral da Pós-Graduação Stricto Sensu em Direito Processual da UERJ

Patrono: José Carlos Barbosa Moreira (in mem.). ISSN 1982-7636. pp. 483-523

www.redp.uerj.br

La separación de funciones es necesaria, pero no puedo soslayarse el permanente diálogo que debe darse entre las acciones jurisdiccionales y las administrativas.

Señala BINDER ${ }^{21}$ que la clara separación entre acciones de gobierno en sentido estricto y las de administración de los tribunales es necesaria, pero ello no quiere decir que no existan fuertes relaciones entre ambas. Agrega:

"¿Quién se hace responsable de administrar a las instituciones judiciales? ¿Cuál es la dimensión específica de esa administración? ¿Qué impacto real tiene en la prestación y en la calidad del servicio judicial? ¿Qué tanto afecta la independencia judicial la mala administración de los recursos? Aunque estas preguntas parecen obvias, nos sorprendería descubrir el grado de desorden, oscuridad y hasta primitivismo que impera en la administración de los tribunales. Pero más sorprendente aún es el hecho de que buena parte de esas decisiones -y no necesariamente las más importantes- son tomadas por jueces "superiores" con grave detrimento para su trabajo jurisdiccional y nula preparación para esa tarea. Es bastante usual que presidentes de tribunales e incluso de las Cortes Supremas terminen participando en miles de expedientes administrativos, sobre temas menores, que deben firmar sin tener posibilidades de control y sin que se trate de decisiones que requieran la participación de altos niveles de gobierno. En el diseño institucional es necesario que las instituciones judiciales separen con claridad jurisdicción, gobierno y administración. Le es exigible a los sistemas judiciales que lo hagan porque la modernización administrativa no es una necesidad interna sino una forma de garantizar un servicio de calidad, a la vez de ser una de las dimensiones que afectan a la independencia judicial de un modo cotidiano y provocado por las mismas instituciones judiciales que suelen ser ciegas ante estos problemas".

El sistema de justicia civil debe diseñar un esquema de organización y gestión acorde con los desafíos actuales, es decir, el incremento de la demanda y la litigiosidad ciudadana, y crecientes niveles de exigencia hacia la calidad, celeridad y eficiencia de los servicios que brinda el Estado, además de la transparencia que hoy se espera en el actuar de toda entidad estatal.

Este modelo debe permitir alcanzar eficaz y eficientemente las metas y objetivos del sistema, siendo un factor crítico la separación de funciones administrativas de las

${ }^{21}$ BINDER, Alberto, Ob. Cit., ps. 26 y 27. 
Revista Eletrônica de Direito Processual - REDP.

Rio de Janeiro. Ano 13. Volume 20. Número 3. Setembro a Dezembro de 2019

Periódico Quadrimestral da Pós-Graduação Stricto Sensu em Direito Processual da UERJ

Patrono: José Carlos Barbosa Moreira (in mem.). ISSN 1982-7636. pp. 483-523

www.redp.uerj.br

jurisdiccionales. Debe comprender un plan global de gestión judicial que aborde los niveles de gobierno, gerencia y despacho, e incorpore tecnologías de información y comunicación - TIC's, planeación estratégica, rediseño organizacional, liderazgos en la administración del Poder Judicial, y programas de capacitación permanente.

Como también se ha señalado desde el Centro de Estudios de Justicia de las Américas $(\mathrm{CEJA})^{22}$ :

"La incorporación de nuevas modalidades de gestión judicial que rompan con la organización judicial piramidal clásica ha demostrado ser la única forma posible de que un código procesal oral pueda ser implementado exitosamente. En la región, existen diversos modelos como las oficinas judiciales, los mega-despachos o la figura del administrador de tribunales, por ejemplo. Independientemente del tipo de modelo seleccionado, existen algunas reformas fundamentales que deben emprenderse en la gestión de los tribunales como la división entre funciones jurisdiccionales y administrativas, la incorporación de profesionales del área de la administración a los juzgados o la implementación de nuevas tecnologías. Los juzgados que históricamente se conformaron con el objetivo último de la construcción del expediente deben reorganizase para atender a una nueva misión principal, la celebración efectiva de audiencias orales".

Señala ARELLANO ${ }^{23}$ que

"la indistinción entre funciones políticas y administrativas dentro del Poder Judicial, principalmente las ejercidas por los ocupantes de altos cargos, ha generado en nuestras sociedades la dificultad de entender y acercarse a la dinámica de la justicia, y entre los mismos miembros de las carreras judiciales el cuestionamiento sobre la imparcialidad y gestión del sistema".

A continuación, se mencionan aspectos que deben tenerse en cuenta en el diseño de un modelo de gestión y en la incorporación de tecnologías de información y comunicación. Cabe

${ }^{22}$ CEJA, "10 Ideas sobre el modelo de reforma a la justicia civil que promueve CEJA en América Latina y el Caribe"

http://www.cejamericas.org/Documentos/2018/10_IdeassobreelmodelodereformaalajusticiacivilquepromueveCEJ AenAmericaLatinayelCaribe_coninfografias.pdf

${ }^{23}$ ARELLANO, Jaime, Ob. Cit., p. 7. 
Revista Eletrônica de Direito Processual - REDP.

Rio de Janeiro. Ano 13. Volume 20. Número 3. Setembro a Dezembro de 2019

Periódico Quadrimestral da Pós-Graduação Stricto Sensu em Direito Processual da UERJ

Patrono: José Carlos Barbosa Moreira (in mem.). ISSN 1982-7636. pp. 483-523

www.redp.uerj.br

señalar que si bien estos análisis y recomendaciones se realizan para la reforma a la justicia civil, la mayoría de ellos son aplicables a cualquier ámbito y jurisdicción del sistema de justicia sean de carácter civil o penal, de primera u otras instancias. De hecho, el paso de sistemas inquisitivos a sistemas adversariales en materia penal produjo en América Latina una fuerte revisión del sistema de gestión, con importantes cambios organizacionales, transformación de prácticas e introducción de nuevos roles y funciones del cual pueden extraerse varias lecciones aprendidas.

\subsection{Contenidos del modelo de gestión}

Como lo hemos señalado con CHAYER y VILLADIEGO ${ }^{24}$, el diseño de un adecuado modelo de gestión debe considerar varios asuntos ${ }^{25}$.

En primer lugar, debe entender que la gestión judicial no es competencia exclusiva de los niveles decisorios de política judicial o de los despachos judiciales, sino que es un conjunto de competencias de distintos órganos e instancias que la diseñan, ejecutan y controlan.

En segundo lugar, el diseño de un modelo adecuado debe introducir las funciones de la gestión:

i) aprobar normas o políticas, es decir, definir los criterios de actuación que deben seguir los distintos niveles de gestión judicial;

ii) ejecutar las políticas, es decir, implementar mecanismos y procesos necesarios para desarrollar las actividades requeridas en los distintos niveles de gestión y;

iii) controlar la gestión, es decir, medir o monitorear en qué medida la ejecución de la gestión se acerca a los objetivos y metas definidos.

\footnotetext{
${ }^{24}$ PEREIRA CAMPOS, Santiago; VILLADIEGO, Carolina y CHAYER, Héctor, Ob. cit., p. 108.

${ }^{25}$ Véase: a) CEJA-, Programa de las Naciones Unidas para el Desarrollo y Ministerio de Justicia de Brasil, "Estudio comparado sobre gestión presupuestaria y gestión administrativa de cortes y tribunales y tratamiento estadístico de la información sobre el funcionamiento del sistema judicial", Santiago, 2006, Disponible en: www.cejamericas.org; b) MARCET, Juan Pablo, "El gobierno del sistema judicial en Argentina: un enfoque organizacional”, en Estudios sobre la Administración de Justicia No 2, Fores, Buenos Aires 2004; y c) VARGAS VIANCOS, Juan Enrique, "Curso sobre instrumentos para la implementación de un sistema acusatorio oral Herramientas para el diseño de Despachos Judiciales”, Viña del Mar, 2006, Disponible en: www.cejamericas.org
} 
Revista Eletrônica de Direito Processual - REDP.

Rio de Janeiro. Ano 13. Volume 20. Número 3. Setembro a Dezembro de 2019

Periódico Quadrimestral da Pós-Graduação Stricto Sensu em Direito Processual da UERJ

Patrono: José Carlos Barbosa Moreira (in mem.). ISSN 1982-7636. pp. 483-523

www.redp.uerj.br

En tercer lugar, el diseño debe fijar un plan global que defina metas y objetivos, la forma de cumplimiento, y las competencias para desarrollarlas en los niveles de gestión judicial de gobierno, gerencia y organización del despacho judicial.

Cada país debe responder a la pregunta ¿quiénes componen los tres niveles de gestión y cuáles son sus funciones específicas? Y tal respuesta debe considerar las disposiciones constitucionales, la organización del sistema de justicia, y que todos los niveles de gestión pueden desarrollar acciones encaminadas a cumplir las tres funciones.

Ahora bien, el nivel de gobierno en la gestión judicial decide aspectos relevantes y estratégicos para el desempeño del sistema de justicia. Puede ser desarrollado por órganos encargados del máximo nivel decisorio, siempre y cuando cuenten con el concurso de profesionales especializados en las áreas de economía, administración, ingeniería de sistemas, entre otros. El nivel de gobierno tiene como función:

- Diseñar reformas a la estructura de la justicia de acuerdo con las reformas legales (sustantivas y/o adjetivas) realizadas.

- Planear estratégicamente a través de objetivos, metas, y resultados.

- Realizar seguimiento a la gestión judicial de las autoridades competentes.

- Establecer los cambios necesarios según los resultados obtenidos.

- Definir la ejecución presupuestal.

- Diseñar los sistemas de control administrativo, incluidos aquellos que permiten el seguimiento procesal.

El nivel de gerencia se encarga de decidir tácticamente la implementación de las decisiones estratégicas tomadas por el nivel de gobierno. Debe ser ejecutado por autoridades profesionales en gerencia y preferiblemente ser centralizado. El nivel tiene como función:

- Realizar la ejecución presupuestal y definir las inversiones y adquisiciones requeridas.

- Asignar los recursos humanos, físicos y financieros a las distintas estructuras del sistema de justicia, incluidos los juzgados, tribunales, y oficinas administrativas.

- Crear y mantener sistemas de información y estadística judicial que permitan la asociación entre la información y las decisiones adoptadas, la homologación de la información y las capacidades analíticas, y la difusión de la información. 
Revista Eletrônica de Direito Processual - REDP.

Rio de Janeiro. Ano 13. Volume 20. Número 3. Setembro a Dezembro de 2019

Periódico Quadrimestral da Pós-Graduação Stricto Sensu em Direito Processual da UERJ

Patrono: José Carlos Barbosa Moreira (in mem.). ISSN 1982-7636. pp. 483-523

www.redp.uerj.br

- Proveer servicios administrativos a los juzgados y tribunales.

- Diseñar un sistema de incentivos para los funcionarios del sistema de justicia que incluya la adopción de buenas prácticas y la ejecución presupuestal asociada a metas.

El nivel de operación del despacho judicial se encarga de la evolución eficaz y eficiente del proceso judicial, independientemente de las diferentes estructuras organizativas que pueden adoptar los despachos.

Debe ser desarrollado por operadores judiciales y administrativos en una relación armónica entre los diferentes roles. Unos y otros tienen conocimientos específicos requeridos para una mejor gestión al interior del despacho. Debe tenerse presente que la autoridad conferida a los funcionarios administrativos es proporcional a su responsabilidad; lo que se conoce como principio de paridad.

Este nivel de gestión tiene como funciones principales:

- Recibir y distribuir las causas ingresadas.

- Definir los procedimientos o procesos de trabajo del despacho judicial, incluidos los relacionados con el archivo de actuaciones, declaratorias de inactividad de procesos, diligencias fuera del despacho (comisiones judiciales), designación de peritos, entre otros.

- Definir los roles y funciones de quienes trabajan en el despacho judicial.

- Definir y organizar la atención al público.

- Efectuar el manejo de la agenda del despacho para realizar distintas diligencias, como por ejemplo, audiencias, inspecciones judiciales, entre otras.

- Administrar y solventar los flujos y cargas de trabajo.

- Fijar metas y objetivos de desempeño del despacho y ejercer control real sobre lo que sucede en el trámite del caso.

Ya se ha mencionado que el nuevo modelo de gestión debe definir las funciones estrictamente jurisdiccionales y separarlas de las administrativas en los tres niveles señalados. Este es uno de los aspectos más relevantes del diseño del modelo de gestión, pues el desarrollo de funciones administrativas por parte de jueces y magistrados consume tiempo importante que 
Revista Eletrônica de Direito Processual - REDP.

Rio de Janeiro. Ano 13. Volume 20. Número 3. Setembro a Dezembro de 2019

Periódico Quadrimestral da Pós-Graduação Stricto Sensu em Direito Processual da UERJ

Patrono: José Carlos Barbosa Moreira (in mem.). ISSN 1982-7636. pp. 483-523

www.redp.uerj.br

debería ser empleado en decisiones de fondo ${ }^{26}$. Adicionalmente, suele suceder que cuando son los jueces los responsables de las funciones administrativas, se produce un traspaso de las normas procesales al ejercicio de la administración (particularmente a nivel de gobierno); y la administración se ve teñida por un ritualismo jurídico que conspira contra la ejecutividad.

La ejecución de las actividades administrativas requiere profesionales especializados en disciplinas distintas al derecho, como por ejemplo, el manejo del archivo, los depósitos judiciales, los sistemas de información, entre otras. Por este motivo, el diseño del modelo de gestión debe:

- Profesionalizar el perfil de los funcionarios requeridos en los tres niveles del modelo, mediante la asignación de competencias y responsabilidades claras a cada uno de ellos. En poderes judiciales donde la mayoría de empleados y funcionarios son estudiantes de materias jurídicas o abogados, se requiere una redefinición del perfil profesional de la planta.

- Administrar de manera profesional el sistema de justicia y contemplar herramientas administrativas requeridas para su funcionamiento efectivo.

- Aprovechar economías de escala en los servicios administrativos que soporten la labor judicial, a través de oficinas comunes que sirvan a una pluralidad de jueces y magistrados, que se encarguen de la radicación, el reparto, las notificaciones, la atención al público, el manejo de salas de audiencia y servicios de peritaje, la ejecución de providencias, entre otras.

Un modelo de gestión más eficiente puede mejorar la capacidad de respuesta de la justicia sin necesidad de un aumento presupuestario. Para facilitar el acceso a la justicia es necesario crear nuevas formas de oferta, distribuir mejor los recursos existentes, y hacer menos rígido el concepto de competencia territorial. En efecto, determinadas actividades y diligencias que impliquen el traslado del usuario, del juez u otro funcionario a lugares distantes, puede requerir

\footnotetext{
${ }^{26}$ En algunos países, como Brasil, muchos jueces destinan una parte significativa de su tiempo a recibir en sus despachos a abogados que van a solicitarle una resolución pronta de los casos. Ello parece inaceptable, no solo desde la óptica del debido proceso (debiera recibir a los abogados de ambas partes conjuntamente), sino desde la óptica de lo que resulta razonable en materia de gestión.
} 
Revista Eletrônica de Direito Processual - REDP.

Rio de Janeiro. Ano 13. Volume 20. Número 3. Setembro a Dezembro de 2019

Periódico Quadrimestral da Pós-Graduação Stricto Sensu em Direito Processual da UERJ

Patrono: José Carlos Barbosa Moreira (in mem.). ISSN 1982-7636. pp. 483-523

www.redp.uerj.br

una desconcentración de funciones en el territorio para la presentación y recepción de demandas y memoriales, realización de inspecciones o comisiones judiciales, entre otros.

Igualmente, el diseño debe considerar las características del territorio y de la población donde se presta el servicio de justicia civil, para determinar la pertinencia de ciertas herramientas de gestión. Es necesario conocer la densidad de la población, su ubicación geográfica respecto de la ubicación de los tribunales, la conectividad informática, entre otros. En efecto, el trámite de un proceso virtual tiene sentido en lugares donde existe conectividad informática y donde los usuarios emplean tecnologías de información y comunicación; por ello, en aquellos lugares donde esto no ocurre, el diseño debe comprender una etapa de transición gradual y otras formas de trámite. Asimismo, la incorporación de servicios comunes requiere analizar previamente la carga de trabajo, y la cantidad actuaciones para las que se requieren dichos servicios.

Además, el modelo de gestión requiere mejorar los procedimientos de trabajo al interior de los despachos judiciales, utilizando intensivamente las tecnologías de información y comunicación que pueden permitir realizar una efectiva administración de la documentación y de los plazos del proceso.

Igualmente, el modelo de gestión debe estar al servicio de la nueva estructura procesal civil, es decir, debe responder al proceso oral o por audiencias, donde las decisiones se toman y fundamentan en audiencia, y comprender distintos estándares de satisfacción de la oralidad.

Así, los procesos sin oposición requieren una plataforma de gestión distinta a la de aquellos contradictorios de mayor o menor complejidad.

En el primer caso, el trámite entero podría efectuarse a través de Internet siempre que se garantice la oralidad cuando exista oposición real del demandado; mientras que en el segundo, se requiere la gestión de una o dos audiencias concentradas, públicas y contradictorias en la que haya inmediación judicial.

Una manera de testear si el modelo de gestión responde verdaderamente al proceso por audiencias u oral con inmediación, es analizar si las causas avanzan en la práctica por la agregación de documentos escritos en un expediente, provenientes de las partes o del tribunal; o por el cumplimiento de plazos y la realización de diligencias con la participación del juez y de las partes. 
Revista Eletrônica de Direito Processual - REDP.

Rio de Janeiro. Ano 13. Volume 20. Número 3. Setembro a Dezembro de 2019

Periódico Quadrimestral da Pós-Graduação Stricto Sensu em Direito Processual da UERJ

Patrono: José Carlos Barbosa Moreira (in mem.). ISSN 1982-7636. pp. 483-523

www.redp.uerj.br

Finalmente, la implementación de un nuevo modelo de gestión acorde con la oralidad requiere una infraestructura física que permita la realización de actuaciones en audiencia, garantice la presencia de las partes y las pruebas en audiencia, promueva la litigación oral efectiva en el proceso, e incorpore mecanismos que garanticen los principios de oralidad aunque las partes se encuentren en otros lugares (videoconferencias).

\subsection{Algunas experiencias innovadoras}

Desde CEJA $^{27}$ se reseñan recientemente algunas experiencias en la reforma de la organización judicial que se han hecho cargo de una doble motivación: por un lado generar órganos jurisdiccionales más horizontales y, por otro lado, generar órganos jurisdiccionales que puedan tener un funcionamiento más eficiente.

a) Los Colegios de Jueces/zas o Juzgados Corporativos

Es de interés en el panorama latinoamericano la aparición de los llamados Colegios de Jueces/zas, Pool de Jueces/zas o Juzgados Corporativos. Ello permite que un mismo juzgado pueda estar conformado por un número determinado de jueces y juezas que ejerzan sus funciones en el ámbito del mismo juzgado. Esto no quiere decir que se rompa con el trabajo unipersonal que deba realizar el juez. Por el contrario, cada juez/a conocerá de los asuntos debidamente asignados por el tribunal de forma individual. Es decir, estaríamos hablando de órganos jurisdiccionales de composición múltiple pero con conocimiento de casos de forma individual. Por lo tanto, a pesar de la similitud conceptual, es importante diferenciar esta estructura de los tribunales colegiados en los cuales a un grupo de jueces/zas se le asigna el conocimiento de un caso o de una etapa procesal de un caso.

De forma paralela al Colegio de Jueces/zas debiese existir una estructura administrativa que preste un servicio de apoyo para las labores que realicen todos los jueces y juezas que integran este juzgado.

b) La justicia itinerante

${ }^{27}$ FANDIÑO, Marco, Ob. cit., ps. 22 y ss. 
Revista Eletrônica de Direito Processual - REDP.

Rio de Janeiro. Ano 13. Volume 20. Número 3. Setembro a Dezembro de 2019

Periódico Quadrimestral da Pós-Graduação Stricto Sensu em Direito Processual da UERJ

Patrono: José Carlos Barbosa Moreira (in mem.). ISSN 1982-7636. pp. 483-523

www.redp.uerj.br

Ante la significativa extensión geográfica de muchos países de Latinoamérica, se generan grandes dificultades en términos de despliegue territorial de los servicios de justicia. Los juzgados y tribunales suelen estar concentrados en sectores céntricos de los núcleos poblacionales lo que genera importantes barreras de acceso a la justicia no sólo en relación a las distancias, sino también en cuanto a los costos necesarios para recorrer dichas distancias.

La justicia itinerante tiene su fundamento en la optimización de los recursos del sistema, ya que en muchos casos la baja carga procesal no justifica la creación de nuevas sedes jurisdiccionales. En estas situaciones, un órgano jurisdiccional móvil podría atender cada día de la semana, por ejemplo, una localidad para atender las necesidades jurídicas de su población, teniendo su asiento en el núcleo poblacional con mayor conflictividad de la zona ${ }^{28}$.

c) Modelos de gestión de la estructura administrativa Señala FANDIÑO ${ }^{29}$ que, al momento de diseñar un modelo de gestión de la carga de trabajo administrativo existente en un Juzgado se pueden distinguir varias modalidades en base a la experiencia internacional. Entre las principales innovaciones se destacan el funcionamiento:

- a través de una Oficina Judicial,

- a través de un administrador de tribunal o

- a través de unidades de servicios comunes.

i. Oficina judicial

Existen numerosas experiencias de Oficinas Judiciales, por ejemplo, en Argentina, donde se destacan los ejemplos de Neuquén o Chubut.

Una de las características principales del modelo de Oficina Judicial es que a cargo de la Oficina se encuentra un/a Director/a, quien debiese tener experiencia y formación en el área de la gestión y administración de recursos públicos o privados ${ }^{30}$.

${ }^{28}$ La experiencia ha tenido aplicación en algunos países latinoamericanos con dificultades territoriales. En Uruguay, en cambio, desde 1989 está prevista en la ley la posibilidad de crear tribunales itinerantes de segunda instancia por zonas el país, pero no se ha implementado.

${ }^{29}$ FANDIÑO, Marco, Ob. cit., ps. 22 y ss.

${ }^{30} \mathrm{La}$ formación jurídica no debe ser un requisito para ejercer la función de Director/a en la Oficina Judicial, pero tampoco deberían excluirse a los licenciados en Derecho de ocupar este cargo, siempre y cuando cuenten con formación complementaria en la gestión y administración de recursos. 
Revista Eletrônica de Direito Processual - REDP.

Rio de Janeiro. Ano 13. Volume 20. Número 3. Setembro a Dezembro de 2019

Periódico Quadrimestral da Pós-Graduação Stricto Sensu em Direito Processual da UERJ

Patrono: José Carlos Barbosa Moreira (in mem.). ISSN 1982-7636. pp. 483-523

www.redp.uerj.br

El resto del personal de la Oficina Judicial suele estar dividido por unidades que tienen a su cargo la realización de una serie de funciones que son de vital importancia para el funcionamiento de un sistema basado, principalmente, en la celebración de audiencias orales. Aquí se visualiza una diferencia fundamental con la forma de gestionar un juzgado con el sistema tradicional-piramidal totalmente diseñado para servir de apoyo a la tramitación por escrito de un expediente. Por el contrario, la Oficina Judicial está totalmente enfocada en la tramitación de casos a través de, principalmente, audiencias orales que serán la fuente de la toma de las principales decisiones del proceso. Este cambio de paradigma va a tener una correlación en las funciones que les asignaremos a las principales unidades que compongan la Oficina Judicial.

Es frecuente que las Oficinas Judiciales se estructuren en las siguientes unidades:

- Unidad de Atención al Público.

- Unidad de Gestión de Casos.

- Unidad de Salas de Audiencias.

- Unidad de Servicios Administrativos.

- Unidad de Notificaciones.

Por su parte, los jueces y las juezas también se encuentran vinculados a la Oficina Judicial -idealmente en un colegio de jueces/zas como vimos con anterioridad-. De hecho, se suele decir que los jueces y juezas son el recurso más valioso del sistema, motivo por el cual se debe priorizar que destinen sus horas de trabajo a cuestiones puramente jurisdiccionales.

Al tratarse de un recurso tan valioso para el sistema, la Oficina Judicial debe disponer de la agenda de los jueces con la finalidad de que se puedan producir el mayor número de audiencias orales y para que el juez no tenga a su cargo ningún tipo de responsabilidad en temas administrativos y no jurisdiccionales.

ii. Administrador de tribunal

Se trata de una suerte de Director/a de Oficina Judicial que también tiene a su cargo un grupo de empleados/as administrativos que están divididos en áreas que realizan funciones especialmente críticas para la celebración de audiencias orales. El/la administrador/a también debiese tener una experiencia y formación relacionada con la gestión y administración de 
Revista Eletrônica de Direito Processual - REDP.

Rio de Janeiro. Ano 13. Volume 20. Número 3. Setembro a Dezembro de 2019

Periódico Quadrimestral da Pós-Graduação Stricto Sensu em Direito Processual da UERJ

Patrono: José Carlos Barbosa Moreira (in mem.). ISSN 1982-7636. pp. 483-523

www.redp.uerj.br

recursos públicos o privados (Administración Pública o de Empresas, Ingeniería Civil, por ejemplo).

Existen pocas diferencias entre el modelo de Oficina Judicial y el de administración de tribunales. En el caso de la Oficina Judicial, esta sería una gran estructura que incluye a todos los recursos administrativos, los cuáles trabajarían para dar apoyo a los juzgados o tribunales que estén adscritos a dicha Oficina Judicial. Por el contrario, en los sistemas de administrador/a de tribunales, todos los/as empleados/as administrativos incluyendo al administrador/a pertenecen al juzgado o tribunal para el que prestan el servicio. A pesar de ello, el/a administrador/a sería el superior jerárquico de todo el staff administrativo del juzgado. Es común que en este tipo de sistemas, los juzgados estén compuestos por un número elevado de jueces y juezas que integran un mismo tribunal.

iii. Servicios comunes

Otra modalidad posible en la gestión de la carga de trabajo administrativa de los juzgados y tribunales es la de Servicios Comunes. En estos casos, señala FANDIÑO ${ }^{31}$, se genera una unidad administrativa independiente a los juzgados con la finalidad de que les preste servicio en un área concreta del trabajo. Es muy frecuente que los servicios comunes asuman la prestación de un servicio de apoyo especializado en alguna tarea.

Uno de los modelos de servicios comunes que más impacto ha tenido son las centrales de notificaciones. La función de notificación a las partes procesales que históricamente ha sido una de las tareas propias de los juzgados, se externaliza a través de una unidad administrativa, cuya misión es proveer las notificaciones en los plazos y forma que los juzgados y tribunales requieran. Además, una sola central de notificaciones puede prestar sus servicios hacia un número bastante amplio de juzgados y tribunales (por ejemplo, a todos los juzgados de una ciudad o de una demarcación judicial). Esta forma de reparto de funciones permite tanto el aprovechamiento de las economías de escala así como también una mayor especialización en el servicio prestado por la unidad de servicios comunes.

\footnotetext{
${ }^{31}$ FANDIÑO, M., Ob. cit., ps. 22 y ss.
} 
Revista Eletrônica de Direito Processual - REDP.

Rio de Janeiro. Ano 13. Volume 20. Número 3. Setembro a Dezembro de 2019

Periódico Quadrimestral da Pós-Graduação Stricto Sensu em Direito Processual da UERJ

Patrono: José Carlos Barbosa Moreira (in mem.). ISSN 1982-7636. pp. 483-523

www.redp.uerj.br

d) El Tribunal Multipuertas y la Gestión de $\operatorname{casos}^{32}$

Señala FANDIÑO ${ }^{33}$ que la aparición de dos nuevos paradigmas procesales que se están formulando suponen en el ámbito académico una revolución no sólo en términos de cómo entendemos el proceso civil, sino también acerca de cuáles son los límites del Derecho Procesal tal y como lo conocemos hasta el momento.

i. $\quad$ El Tribunal Multipuertas ${ }^{34}$

La idea del Tribunal Multipuertas o Multi-Door Courthouse fue acuñada por el profesor de la Universidad de Harvard Frank E.A. SANDER ${ }^{35}$.

El Tribunal Multipuertas se basa en la idea de una oficina o juzgado a donde lleguen los conflictos y en donde estos puedan ser evaluados y derivados a aquella modalidad de solución que sea más adecuada según las características del caso particular.

Como señala FANDIÑO ${ }^{36}$, el trabajo del Tribunal Multipuertas se inicia en una primera etapa llamada "lobby". En esta etapa se intenta que el caso pueda ser resuelto antes incluso de que sea evaluado y que sea derivado a alguna instancia de resolución de conflictos. De esta forma se intentará ofrecer la información y orientación jurídica necesaria a la persona que haga conocer su conflicto o que quiera presentar su demanda. En la medida de lo posible se buscará que el conflicto pueda ser resuelto con una negociación privada por las partes del conflicto. Una vez el conflicto es formalmente declarado e ingresado al tribunal multipuertas, se realiza una evaluación del conflicto.

En algunos estados de Estados Unidos, la evaluación del caso es realizada por jueces/ zas jubilados con gran conocimiento y experiencia en el manejo de conflictos. En las Unidades de Justicia Vecinal de Chile (que adoptan un funcionamiento bajo el modelo del Multi-Door Courthouse) este trabajo de evaluación lo realizan tres profesionales (psicólogos/as, abogados/as o trabajadores/as sociales).

\footnotetext{
${ }^{32}$ Seguimos en este apartado los estudios que se han realizado desde CEJA y especialmente el de FANDIÑO, M., Ob. cit., ps. 28 y ss.

${ }^{33}$ FANDIÑO, M., Ob. cit., ps. 28 y ss.

${ }^{34}$ Seguimos los estudios de CEJA y especialmente a FANDIÑO, M., "Ob. cit. ps. 28 y ss.

${ }^{35}$ Esta idea se dio a conocer por primera vez en el año 1976 en el contexto de los debates sobre Alternative Dispute Resolution (ADR). Desde su creación el Tribunal Multipuertas se ha expandido rápidamente por varios estados de Estados Unidos, así como por otros países como Canadá o Nigeria.

${ }^{36}$ FANDIÑO, M., Ob. cit., ps. 28 y ss.
} 
Revista Eletrônica de Direito Processual - REDP.

Rio de Janeiro. Ano 13. Volume 20. Número 3. Setembro a Dezembro de 2019

Periódico Quadrimestral da Pós-Graduação Stricto Sensu em Direito Processual da UERJ

Patrono: José Carlos Barbosa Moreira (in mem.). ISSN 1982-7636. pp. 483-523

www.redp.uerj.br

En función del resultado de la evaluación del caso, se tomará una decisión acerca de su derivación a la instancia que resulte más adecuada para su resolución. En ese sentido, existen diversos métodos de solución en los que el conflicto podrá ser resuelto. El conflicto podría ser derivado a una instancia de mediación, arbitraje, conciliación de med-arb (Método híbrido que se compone de una primera fase de mediación y otra de arbitraje) o puede ser resuelto adjudicativamente de forma directa por el propio juez. También existen experiencias en las que estas formas de resolver conflictos se especializan en función de la materia y por lo tanto se puede obtener un tratamiento más sofisticado del conflicto (derivación a mediador especializado en conflictos familiares o de consumo, por ejemplo) ${ }^{37}$.

Una de las falencias en el comportamiento del Multi-Door Courthouse en América Latina ha sido el hecho de que no existe una conexión adecuada con los tribunales o que directamente no están vinculados. Esta situación genera un impacto negativo en la ciudadanía, que tiende a no asistir a las audiencias de mediación o a incumplir los acuerdos al no estar presente el llamado efecto de sombra de la ley .

En el último tiempo se han podido constatar algunos ejemplos muy relevantes sobre cómo la idea de Tribunal Multipuertas fue incorporada como un elemento fundamental a la hora de concebir los principios rectores de los nuevos procesos civiles en la región. El nuevo Código de Processo Civil de Brasil tiene un reconocimiento expreso a la existencia de múltiples métodos consensuales de solución de conflictos, y se establece una visión no neutral en cuanto al uso de estos métodos. De hecho, se indica en el nuevo Código Procesal Civil que el "Estado deberá promover siempre que sea posible la solución consensual de los conflictos”. Sin lugar a dudas, este reconocimiento indica que a los ojos del Estado no es indiferente que un mismo conflicto pueda resolverse en la vía adjudicativa o en la vía consensual. Por el contrario, siempre que sea posible, se debe preferir que el Estado promueva la solución acordada como una garantía para

\footnotetext{
${ }^{37}$ En América Latina, el modelo Multi-Door Courthouse se ha empleado en diversas instituciones, en Argentina por ejemplo es frecuente escuchar y leer la expresión "oficina multipuertas" donde se elimina cualquier referencia a un órgano jurisdiccional. Por otro lado, también ha sido utilizado en modelos como las Casas de Justicia, las cuales a su vez cumplen la función de acercar el funcionamiento del sistema de justicia a las poblaciones más alejadas. Del mismo modo, también ha sido utilizado en experiencias como los Centros Integrados de Justicia en Bolivia o las Unidades de Justicia Vecinal en Chile, por mencionar algunos ejemplos (FANDIÑO, M., Ob. cit., ps. 29 y ss).
} 
Revista Eletrônica de Direito Processual - REDP.

Rio de Janeiro. Ano 13. Volume 20. Número 3. Setembro a Dezembro de 2019

Periódico Quadrimestral da Pós-Graduação Stricto Sensu em Direito Processual da UERJ

Patrono: José Carlos Barbosa Moreira (in mem.). ISSN 1982-7636. pp. 483-523

www.redp.uerj.br

la eficiencia del sistema de justicia y para favorecer una cultura de paz y no violencia entre la población. Además, la doctrina brasilera liderada por MARINONI ${ }^{38}$ ha incursionado en el desarrollo de esta legislación, indicando que en el código se establece el principio fundamental de lo que ellos han denominado Justicia Multipuertas. En ese sentido, los autores establecen una serie de ideas que gravitan entorno a este concepto:

- Es necesario hablar de métodos consensuales de solución de conflictos y no de métodos alternativos.

- Existe un reconocimiento de que los métodos consensuales de solución de conflictos son más idóneos para resolver determinados conflictos, como por ejemplo los conflictos familiares.

- Hay que abandonar la idea del sistema de justicia como una única puerta para referirnos a una Justicia Multipuertas en la que el sistema encargado de administrar justicia debe identificar el método apropiado para cada tipo de litigio.

Otro ejemplo significativo que permite sostener la irrupción de este nuevo paradigma es la reciente legislación procesal civil de Quebec en Canadá del año 2014 ${ }^{39}$. En este caso, encontramos una consagración semejante en cuanto a los principios generales que el sistema procesal civil establece. Se señala que para prevenir una disputa potencial o resolver una existente, las partes interesadas, por mutuo acuerdo, pueden optar por un proceso privado de prevención y resolución de disputas. Los principales procesos privados de prevención y resolución de disputas son la negociación entre las partes y la mediación y el arbitraje, en las que las partes recurren a una tercera persona para que los asista. Las partes también pueden recurrir a cualquier otro proceso que consideren apropiado, ya sea con características de negociación, mediación o arbitraje o no. Las partes deben considerar los procesos privados de prevención y resolución antes de remitir su disputa a los tribunales.

Como podemos observar, se repite nuevamente el esquema seguido por la legislación brasilera, lo que supone, en primer lugar, el reconocimiento amplio de una diversidad de

\footnotetext{
${ }^{38}$ MARINONI, L.; ARENHART, S., MITIDIERO, D., "Novo Código de Processo Civil comentado", Thomson Reuters-Revista dos Tribunais, Brasil, 2016.

${ }^{39}$ Relevado por FANDIÑO, M., Ob cit., p. 30 y ss.
} 
Revista Eletrônica de Direito Processual - REDP.

Rio de Janeiro. Ano 13. Volume 20. Número 3. Setembro a Dezembro de 2019

Periódico Quadrimestral da Pós-Graduação Stricto Sensu em Direito Processual da UERJ

Patrono: José Carlos Barbosa Moreira (in mem.). ISSN 1982-7636. pp. 483-523

www.redp.uerj.br

modalidades públicas y privadas y, por otro lado, el reconocimiento del compromiso del Estado por promover la solución consensual de los conflictos.

En el caso de Quebec, PICHÉ y NOREAU ${ }^{40}$ indican que la doctrina ha mencionado que este importante cambio en la forma de entender el sistema judicial, supone la consolidación de una nueva cultura jurídica ${ }^{41}$. Según estas nuevas aproximaciones al ámbito del proceso civil, ya no existe una visión de "monismo jurídico" según la cual solamente existe el proceso judicial para resolver conflictos civiles. Por el contrario, este nuevo paradigma establece un nuevo enfoque según el cual los conflictos civiles pueden ser resueltos indiferentemente a través de instancias públicas o privadas, en donde el proceso judicial es solamente una de las opciones posibles ${ }^{42}$. De hecho, el proceso judicial debiese ser la última alternativa a utilizar, sólo en aquellos casos en los que no se ha podido alcanzar un acuerdo.

Como señala FANDIÑO ${ }^{43}$, nuestra realidad, según la cual existe un reconocimiento oficial de que los conflictos civiles puedan ser resueltos por la justicia ordinaria o bien ante un tercero (ya sea este un funcionario público o un privado) así como las legislaciones de avanzada que proclaman la igualdad total de estos métodos de resolución, nos permite pensar que el pluralismo jurídico tiene total vigencia en el ámbito civil. La consolidación del sistema de arbitraje en muchos países es una prueba fehaciente de este fenómeno. En definitiva, este nuevo paradigma procesal en el que los mecanismos privados (autocompositivos como la mediación o adjudicativos como el arbitraje) se interrelacionan en pie de igualdad con el proceso judicial

\footnotetext{
${ }^{40}$ PICHÉ, C. Y NOREAU, P. "Reformas a la Justicia Civil en Quebec y Canadá". Centro de Estudios de Justicia de las Américas, 2018, citado por FANDIÑO, M., Ob cit., ps 31 y ss.

${ }^{41}$ A estos efectos, resulta fundamental el aporte del profesor inglés Neil Andrews quien utiliza la metáfora de la composición de doble hélice del ADN para referirse al sistema de justicia civil como la "compleja interacción de mutuo apoyo entre el sistema de justicia y los mecanismos no judiciales. La idea expresa la metáfora de que existe una hélice basada en los Mecanismos Alternativos de Solución de Conflictos -incluyendo el arbitraje y la mediación - y otra hélice basada en el proceso judicial pero ambas son complementarias y están entrelazadas" (ANDREWS, 2012, p. 247), ciitado por FANDIÑO, M., Ob. cit., ps. 32 y ss.).

${ }^{42}$ Esta aparición de una nueva cultura jurídica, nos invita a pensar en la consolidación de un paradigma de pluralismo jurídico en materias civiles. El concepto del pluralismo jurídico en América Latina tiene un fuerte arraigo debido al reconocimiento de la justicia indígena que permite que en un mismo Estado existan diversos sistemas jurídicos: uno de carácter eurocéntrico y otro indocéntrico (DE SOUSA, 2007). Esta visión, que resulta completamente válida y acorde a la realidad política, social y constitucional de los países latinoamericanos, también podemos interpretarla en clave expansiva y analizar cómo se manifiesta en el ámbito de la resolución de conflictos civiles (citado por FANDIÑO, M., Ob. cit., ps. 32 y ss.).
}

${ }^{43}$ FANDIÑO, M., Ob. cit., ps. 34 y 35. 
Revista Eletrônica de Direito Processual - REDP.

Rio de Janeiro. Ano 13. Volume 20. Número 3. Setembro a Dezembro de 2019

Periódico Quadrimestral da Pós-Graduação Stricto Sensu em Direito Processual da UERJ

Patrono: José Carlos Barbosa Moreira (in mem.). ISSN 1982-7636. pp. 483-523

www.redp.uerj.br

tradicional, va a tener un enorme impacto en la modalidad en que organizamos del juzgados civiles.

ii. La gestión de casos (case management)

GARCÍA ODGERS ${ }^{44}$ señala:

\begin{abstract}
"El case management es un mecanismo de eficiencia procesal, según el cual, el sistema judicial, en general, y los jueces, en los casos particulares se constituyen en responsables del desarrollo de la litigación, cuyo propósito es asegurar, en la operatoria misma del sistema, el cumplimiento de diversos objetivos procesales. Esta actividad o función, decanta en la operatoria del sistema judicial bajo la forma de criterios de organización, distribución de recursos y decisiones procesales colectivas o individuales que incorporan la proporcionalidad como rasgo más distintivo, orientando tanto la forma como se procesa el conjunto de la litigación, como el curso y tratamiento específico de los casos individuales."
\end{abstract}

A nivel internacional, se ha expandido la herramienta del case management como una forma de trabajo en la que jueces y juezas toman el control y protagonismo del proceso para tratar los casos de forma proporcional a su complejidad, para que la resolución del caso pueda ser lo más eficiente posible. Señala FANDIÑO ${ }^{45}$ que previamente al surgimiento del case management se había constado una debilidad en los procesos civiles puramente adversariales debido a las amplias facultades procesales de las partes en detrimento de la judicatura, lo que en varios países generó problemas de encarecimiento de los procesos y aumento de los tiempos de duración.

Son especialmente relevantes las experiencias de Reino Unido y Australia, así como de Canadá en algunas áreas, tomándose la decisión de concederle a los tribunales amplios poderes de gestión y dirección de los casos sometidos a su conocimiento. El tribunal asume una mayor

\footnotetext{
${ }^{44}$ GARCÍA, R. "Develación, Diagnóstico y Proyecciones del judicial case management en Chile, desde la perspectiva del derecho comparado", 2018, Tesis. Pontificia Universidad Católica de Valparaíso citado por FANDIÑO. M., Ob. cit. p. 38.

${ }^{45}$ FANDIÑO, M., Ob. cit., p. 35.
} 
Revista Eletrônica de Direito Processual - REDP.

Rio de Janeiro. Ano 13. Volume 20. Número 3. Setembro a Dezembro de 2019

Periódico Quadrimestral da Pós-Graduação Stricto Sensu em Direito Processual da UERJ

Patrono: José Carlos Barbosa Moreira (in mem.). ISSN 1982-7636. pp. 483-523

www.redp.uerj.br

responsabilidad por el progreso de los casos para garantizar que los recursos del tribunal se desplieguen adecuadamente y se reduzcan las demoras y retrasos judiciales.

\section{LAS TECNOLOGÍAS DE INFORMACIÓN Y COMUNICACIÓN (TIC’S) EN EL SISTEMA DE JUSTICIA CIVIL}

Como señala LILLO $^{46}$, desde hace unos pocos años estamos viviendo el pasaje del egovernment a la e-justicia. En efecto, desde hace más de una década han sido las instituciones pertenecientes a la rama de gobierno o del "Ejecutivo" las que han ido evolucionando en el uso de las TICs. Esta tendencia surge después de los noventa como reflejo del aumento de la eficiencia que tuvo el comercio electrónico en el mundo privado. La incorporación del gobierno electrónico al sector justicia es lo que se ha conocido como e-justicia, concepto referido básicamente al uso de tecnología, particularmente de la Internet, como herramienta para lograr una mayor relación con el ciudadano, fomentar la participación ciudadana, eliminar barreras de acceso a la justicia, promover la transparencia y rendición de cuentas, lograr una mayor relación inter-institucional y en general brindar un servicio judicial más eficiente.

Es hoy esencial la incorporación permanente de las nuevas tecnologías en el sistema de justicia civil, su gestión, la consulta de los procesos, el expediente electrónico, las notificaciones electrónicas (en algunos países la sola incorporación de este elemento implico un cambio muy significativo), la forma de introducir las pruebas en soporte electrónico al proceso, el registro en audio y/o video de las audiencias, etc.

El diseño de un nuevo modelo de gestión debe utilizar de manera específica tecnologías de información y comunicación -TIC's $\mathrm{s}^{47}$.

Para ello, como lo hemos señalado con CHAYER y VILLADIEGO ${ }^{48}$, se debe elegir, adaptar y poner en funcionamiento prácticas de trabajo que empleen TIC's, y:

\footnotetext{
${ }^{46}$ LILLO, Ricardo, Ob. cit., p. 7.

47 Véase: Centro de Estudios de Justicia de las Américas -CEJA y Microsoft, Libro Blanco de E - Justicia: Perspectivas de uso e impactos de las TIC en la administración de justicia en América Latina, Santiago, Agosto 2008. Disponible online en: www.cejamericas.org

48 PEREIRA CAMPOS, Santiago; VILLADIEGO, Carolina y CHAYER, Héctor, Ob. cit., ps. 112 y ss.
} 
Revista Eletrônica de Direito Processual - REDP.

Rio de Janeiro. Ano 13. Volume 20. Número 3. Setembro a Dezembro de 2019

Periódico Quadrimestral da Pós-Graduação Stricto Sensu em Direito Processual da UERJ

Patrono: José Carlos Barbosa Moreira (in mem.). ISSN 1982-7636. pp. 483-523

www.redp.uerj.br

i) aumenten la productividad y la calidad del sistema de justicia;

ii) reduzcan los costos de operación y;

iii) mantengan la comunicación entre las partes y el juez.

A través de las TICs se ha logrado, a modo de ejemplo:

- transformar en electrónicas las presentaciones de demandas y memoriales;

- registrar adecuadamente audiencias y actuaciones sin quitar espontaneidad a la actividad.

- reemplazar inspecciones y comisiones judiciales por accesos a bases de datos en línea (con las debidas garantías del habeas data);

- realización de videoconferencias que permiten interrogar a personas (partes, testigos, peritos) ubicadas en distintas regiones de un país o en distintos países;

- eliminar el proceso de archivo de procesos físicos implementando el proceso digital;

- restringir el uso de correo postal en notificaciones y citaciones;

- tramitar el proceso on line en casos simples o en los de baja probabilidad de oposición.

Las TIC's desempeñan actualmente tres funciones esenciales en el sistema de justicia:

i) colaborar con la tramitación de los procesos y controlar su desarrollo;

ii) administrar la información de las actividades de los despachos judiciales y;

iii) administrar de manera eficiente los recursos.

Su utilización específica permite:

- Controlar certeramente el estado de los procesos, las actuaciones relevantes realizadas en los plazos ocurridos, a través de flujos de trabajo (workflow).

- Facilitar la comunicación interna del sistema de justicia civil que permita, por ejemplo, agendar salas de audiencia de manera eficiente, registrar de manera oportuna la cancelación de una audiencia por falta de notificación a las partes, consultar el desarrollo de comisiones judiciales, entre otras.

- Facilitar la comunicación externa con usuarios y autoridades públicas o privadas requeridas en los procesos, que facilite el conocimiento de las actuaciones judiciales y administrativas y la rendición de cuentas, y brinde herramientas concretas para mejorar la litigación. 
Revista Eletrônica de Direito Processual - REDP.

Rio de Janeiro. Ano 13. Volume 20. Número 3. Setembro a Dezembro de 2019

Periódico Quadrimestral da Pós-Graduação Stricto Sensu em Direito Processual da UERJ

Patrono: José Carlos Barbosa Moreira (in mem.). ISSN 1982-7636. pp. 483-523

www.redp.uerj.br

- Emplear medios probatorios electrónicos y establecer un esquema de notificación que permita realizar este trámite a través de correos electrónicos, que cuente con seguridad y trazabilidad.

- Permitir el acceso a la información de otras instancias cuyos trámites son altamente relevantes en la justicia civil, tales como, registros inmobiliarios y mobiliarios, bancos donde se depositan títulos judiciales, instituciones que realizan remates, entre otros.

- Promover el acceso a la justicia de personas localizadas en lugares distantes a los despachos judiciales o con dificultades de movilidad, mediante la utilización de medios tecnológicos que acerquen la justicia a las personas.

- Realizar el registro y archivo electrónico de actuaciones procesales con seguridad de datos, (definición de restricciones y publicidad), mediante su almacenamiento adecuado y la incorporación de mecanismos para evitar su desactualización, falseamiento de información, o carencia de alimentación del sistema.

- Procesar y analizar información de apoyo para las decisiones judiciales, como por ejemplo, la consulta de jurisprudencia.

- Utilizar TIC's para la homologación de acuerdos derivados de mecanismos de solución de conflictos distintos al proceso judicial.

- Apoyo en el proceso de ejecución, con la realización de publicidad electrónica de las subastas y la propia subasta a través de sistemas en la web que aseguran difusión, mayor participación y evitan corruptelas.

- Permitir el entrenamiento y capacitación permanente de los funcionarios del sistema de justicia y desarrollar metodologías de enseñanza.

- Permitir medir, valorar y promover la generación y publicación de información judicial en las páginas web del los poderes judiciales respondiendo a la necesidad cada vez más extendida del acceso a la información pública y el reclamo social de transparencia respecto del sistema de justicia ${ }^{49}$.

\footnotetext{
${ }^{49}$ Así, merece especial destaque el Índice de Accesibilidad a la Información Judicial en Internet (IAcc) elaborado por CEJA, que es un instrumento que tiene por objetivo medir y promover la transparencia activa por parte de los Poderes Judiciales y Ministerios Públicos del continente americano.
} 
Revista Eletrônica de Direito Processual - REDP.

Rio de Janeiro. Ano 13. Volume 20. Número 3. Setembro a Dezembro de 2019

Periódico Quadrimestral da Pós-Graduação Stricto Sensu em Direito Processual da UERJ

Patrono: José Carlos Barbosa Moreira (in mem.). ISSN 1982-7636. pp. 483-523

www.redp.uerj.br

Además, las tecnologías de información y comunicación pueden colaborar con la tramitación de procesos judiciales, controlar su desarrollo, y mejorar los procedimientos de trabajo en los despachos judiciales. Puede incorporarse un sistema de seguimiento procesal que fiscalice el avance del proceso y consolide sistemas de control de gestión y administrativos. Su diseño debe responder una pregunta, ¿para qué estructura procesal civil se efectúa? Una respuesta debe considerar que tiene distintas características si se establece para procesos escritos, orales, o para aquellos casos que constituyen un alto volumen o son repetitivos.

No obstante lo anterior, todos los sistemas de seguimiento procesal deben:

- Incorporar los datos generales del proceso civil, sus movimientos, y el estado de tramitación.

- Soportar el registro de todos los datos relevantes del proceso con fines estadísticos, teniendo presente que dicho registro debe ser efectuado por distintos usuarios: jueces, auxiliares judiciales y administrativos, partes, entre otros.

- Apoyar la labor judicial de actualización legal y jurisprudencial para la solución específica de casos concretos.

- Permitir la introducción de cambios procesales legales.

- Permitir el control de usuario, modo, tiempo y lugar de acceso al sistema, es decir, ser trazable.

El diseño de cada uno de los distintos sistemas de seguimiento procesal presenta características particulares.

En primer lugar, el diseño de aquellos efectuados para procesos escritos puede ser de tramitación de expedientes o de registro de actuaciones. El primero contiene el expediente electrónico, es decir, carga todas las actuaciones allegadas al proceso judicial y cuenta con un sistema de seguridad y de autenticación de documentos, usualmente a través de la firma digital ${ }^{50}$. El segundo, registra las actuaciones de manera resumida, y por lo tanto, no permite conocerlas

\footnotetext{
${ }^{50}$ En algunos países la implementación del expediente digital o electrónico ha sido la excusa perfecta para no implementar el proceso civil por audiencias con inmediación plena. Pero no debemos dejar de considerar que el proceso escrito, sea en papel o digital, termina siendo desde el punto de vista esencial la misma cosa, sin desmerecer las ventajas de ahorro y eficiencia de la digitalización del expediente.
} 
Revista Eletrônica de Direito Processual - REDP.

Rio de Janeiro. Ano 13. Volume 20. Número 3. Setembro a Dezembro de 2019

Periódico Quadrimestral da Pós-Graduação Stricto Sensu em Direito Processual da UERJ

Patrono: José Carlos Barbosa Moreira (in mem.). ISSN 1982-7636. pp. 483-523

www.redp.uerj.br

a detalle, pero permite conocer quién las hizo con un sistema de seguridad que evita alteraciones o manipulaciones de dichas actuaciones.

En segundo lugar, el diseño de aquellos efectuados para procesos por audiencias u orales con inmeidación plena, debe considerar un sistema que permita la incorporación de documentos en papel y realice el registro y apoyo de las audiencias orales que fundamentan las decisiones judiciales.

En tercer lugar, el diseño de aquellos efectuados para procesos que tratan asuntos que generan un alto volumen de casos o que son repetitivos (cobranzas de deudas sin oposición, conflictos vecinales, conflictos derivados del derecho de consumo), puede:

i) ser sencillo y de bajo costo y mantenimiento;

ii) contener funciones especiales para la resolución de casos estandarizados a través de providencias tipo y;

iii) funcionar con baja infraestructura tecnológica y de comunicaciones.

En cuarto lugar, se recomienda que la introducción de tecnologías de información y comunicación se realice de manera subordinada al modelo de gestión. Esto implica que las prácticas judiciales y modelos organizacionales deben revisarse antes de definir las herramientas y soluciones tecnológicas a adoptar. Como resulta evidente, deben responder también al modelo procesal vigente. De esto depende los requerimientos funcionales del sistema, y las pautas para determinar el camino de implementación a seguir: gradualismo, experiencias pilotos o implantación generalizadas, entre otras.

Finalmente, un capítulo aparte lo constituye la utilización de modo más intensivo de la Inteligencia Artificial (IA) en el sistema de justicia.

Siguiendo a NIEVA-FENOLL ${ }^{51}$ si bien ya hay elementos básicos de IA en los sistemas de justicia, como son los buscadores de jurisprudencia o de trabajos doctrinales, correctores, etc., quizás esta forma avanzada de la tecnología está más presente hoy en los sistemas arbitrales o en los grandes despachos de abogados que en los poderes judiciales, generalmente más limitados de recursos.

${ }^{51}$ NIEVA-FENOLL, Jordi, “Inteligencia artificial y proceso judicial”, Marcial Pons, Madid, 2018, p. 14. 
Revista Eletrônica de Direito Processual - REDP.

Rio de Janeiro. Ano 13. Volume 20. Número 3. Setembro a Dezembro de 2019

Periódico Quadrimestral da Pós-Graduação Stricto Sensu em Direito Processual da UERJ

Patrono: José Carlos Barbosa Moreira (in mem.). ISSN 1982-7636. pp. 483-523

www.redp.uerj.br

La aplicación cada vez más extensiva de la IA conlleva grandes desafíos por el riesgo de control ideológico que ello puede conllevar.

Como señala HARARI ${ }^{52}$, puede decirse que "algoritmo" "es el concepto más importante en nuestro mundo. Si queremos comprender nuestra vida y nuestro futuro, debemos hacer todos los esfuerzos posibles por entender que es un algoritmo y como los algoritmos están conectados con las emociones”. Y agrega: “Un algoritmo es un conjunto metódico de pasos que pueden emplearse para hacer cálculos, resolver problemas y alcanzar decisiones. Un algoritmo no es un cálculo concreto, sino el método que se sigue cuando se hace el cálculo”.

Los algoritmos, pueden estar "infectados" de "prejuicios" si la información antecedente sobre la que construye la IA sus decisiones contiene prejuicios ${ }^{53}$.

Tal situación pone en crisis incluso la idea de objetividad, neutralidad, independencia y hasta libre albedrío.

En una reciente publicación señala $\operatorname{PASCUAL}^{54}$ que la matemática y activista Cathy O’NEIL dice que los algoritmos son “opiniones encerradas en matemáticas”. Dependiendo de quién construya esos modelos, qué variables tenga en cuenta y con qué datos se les nutra, darán uno u otro resultado. Por ende, también el desafío ético es inmenso ${ }^{55}$.

\footnotetext{
52 HARARI, Yuval, “Homo Deus - Breve historia del mañana”, Debate, Montevideo, 2018, p. 100.

${ }^{53}$ Así, por ejemplo, los algoritmos demuestran tener prejuicios raciales y de género cuando se les encomienda la selección de personal. Señala PASCUAL que ante la avalancha de currículums que suelen recibir muchas de las grandes multinacionales estadounidenses, es muy común que cada compañía desarrolle lectores de CV para hacer un primer filtrado. Y estos cribados no son neutros. Un grupo de investigadores del MIT envió en 2002, cuando estos sistemas todavía no estaban generalizados, 5.000 currículums a ofertas de trabajo publicadas en periódicos. La mitad de los perfiles inventados tenían nombres típicamente blancos, como Emily Wash, y la otra mitad nombres típicamente negros, como Jamaal Jones. Los resultados fueron significativos: los perfiles blancos recibieron un $50 \%$ más de llamadas. Los sesgos por género también son habituales en la selección de personal.

La introducción de biombos en las audiciones de músicos multiplicó por cinco la presencia femenina en las orquestas que apostaron por esta práctica.

En un artículo ya clásico firmado por un grupo de profesores de la Universidad de Boston, los autores demostraron que los sistemas de machine learning tienen sesgos sexistas porque en la fuente de datos más habitual, esto es, Internet, abundan asociaciones de conceptos que llevan a la máquina a establecer correlaciones como ama de casaella o genio-él. O dicho de otro modo: el algoritmo reproduce los sesgos que de hecho existen en los registros (PASCUAL, Manuel G. ¿Quién vigila que los algoritmos no sean racistas o sexistas?)

https://retina.elpais.com/retina/2019/03/14/tendencias/1552564034_268678.html.

${ }^{54}$ PASCUAL, Manuel G., Ob. cit.

${ }^{55}$ LUENGO-OROZ señala que el aspecto ético debe de estar presente en toda la cadena de la IA, no solo en el propósito del uso de la máscara. Pone un ejemplo muy claro. Imaginemos que queremos crear una máscara para decidir qué currículum seleccionar para la entrevista de entre miles de candidatos que quieren trabajar en nuestra empresa. Para crear la máscara, usamos los datos de la gente que la empresa ha contratado y han triunfado en el
} 
Revista Eletrônica de Direito Processual - REDP.

Rio de Janeiro. Ano 13. Volume 20. Número 3. Setembro a Dezembro de 2019

Periódico Quadrimestral da Pós-Graduação Stricto Sensu em Direito Processual da UERJ

Patrono: José Carlos Barbosa Moreira (in mem.). ISSN 1982-7636. pp. 483-523

www.redp.uerj.br

Como señala HARARI ${ }^{56}$, "la contradicción entre libre albedrio y ciencia contemporánea es el elefante en el laboratorio, al que muchos prefieren no ver mientras miran por sus microscopios y sus escáneres fMRI”.

Por su parte, dice NIEVA-FENOLL ${ }^{57}$ con razón, que vivimos absolutamente rodeados de inteligencia artificial y nunca antes había sido tan sencillo conducir a la población hacia una determinada opción sintiéndose la misma perfectamente libre.

Explica Virginia EUBANKS 58 "Solemos pensar que los algoritmos son neutros, pero no es así. Los sesgos son estructurales y sistémicos, tienen poco que ver con una decisión individual $" 59$.

Los desafíos que la IA plantea son inmensos. HARARI ${ }^{60}$ los plantea de este modo:

“¿Qué le ocurrirá al mercado laboral cuando la inteligencia artificial consiga mejores resultados que los humanos en la mayoría de las tareas cognitivas? ¿Cuál será el impacto político de una enorme clase nueva de personas inútiles desde el punto de vista económico? ¿Qué le ocurrirá a las relaciones, la familias y los fondos de pensiones cuando la nanotecnología y la medicina regenerativa conviertan a la gente de ochenta años en las nuevas personas de cincuenta? ¿Qué le ocurrirá a la sociedad humana cuando la biotecnología nos permita tener bebés de diseño y abrir brechas sin precedentes entre los ricos y pobres?"

Agrega más adelante en términos un tanto apoteósicos:

pasado, así la máscara tendrá el patrón del empleado perfecto. Ese empleado resultaría ser un hombre, puesto que en la empresa hay más hombres que mujeres y la máscara que hemos creado ha identificado el género masculino como parte del patrón de empleado perfecto. La máscara de selección de currículums discriminará por género. Las máscaras (los modelos) son el espejo de los datos que se usan para entrenar al sistema de IA (LUENGO-OROZ, Miguel, "La inteligencia artificial tiene una deuda contigo" en https://retina.elpais.com/retina/2019/01/04/tendencias/1546604928_551805.html).

${ }^{56}$ HARARI, Yuval, Ob. cit., p. 312.

${ }^{57}$ NIEVA-FENOLL, Jordi, Ob. cit., p. 14.

${ }^{58}$ Virginia EUBANKS es profesora de Ciencias Políticas de la Universidad de Albany (Nueva York) y autora de "Automating inequality", un libro que bucea en los sesgos socioeconómicos de los algoritmos con un subtítulo significativo: "Cómo las herramientas tecnológicas perfilan, controlan y castigan a los pobres”.

59 Se preguntaba en 2015 el profesor de medios digitales Taylor OWEN en su artículo "La violencia de los algoritmos": "Estamos construyendo una vasta representación $3 D$ y en tiempo real del mundo. Un registro permanente de nosotros mismos. Pero, ¿qué significado tienen estos datos?”, La respuesta es perturbadora. Muchos de los fallos que tienen los algoritmos aplicados a cuestiones sociales tienen que ver con un error de base: los algoritmos trabajan sobre probabilidades, no con certezas. A menudo se confunden ambas cosas (PASCUAL, Manuel G. Ob. cit.).

${ }^{60}$ HARARI, Yuval, Ob. Cit., p. 299. 
Revista Eletrônica de Direito Processual - REDP.

Rio de Janeiro. Ano 13. Volume 20. Número 3. Setembro a Dezembro de 2019

Periódico Quadrimestral da Pós-Graduação Stricto Sensu em Direito Processual da UERJ

Patrono: José Carlos Barbosa Moreira (in mem.). ISSN 1982-7636. pp. 483-523

www.redp.uerj.br

"A principios del siglo XXI, el tren de progreso sale de nuevo de la estación... y es probable que sea el último tren que salga de la estación llamada Homo sapiens. Los que pierdan el tren nunca tendrán una segunda oportunidad. Si queremos conseguir un pasaje para dicho tren, debemos entender la tecnología del siglo XXI, y en particular los poderes de la biotecnología y de los algoritmos informáticos. Estos poderes son mucho más potentes que el vapor y el telégrafo, y no solo se emplearán en la producción de alimento, tejidos, vehículos y armas. Los principales productos del siglo XXI serán cuerpos, cerebros y mentes, y la brecha entre los que saben cómo modificar cuerpos y cerebro y los que no será mucho mayor que la que existió entre la Gran Bretaña de Dickens y el Sudán de Mahdi. De hecho, será mayor que la brecha entre sapiens y neandertales. En el siglo XXI, los que viajen en el tren del progreso adquirirán capacidades divinas de creación y destrucción, mientras que los que se queden rezagados se enfrentarán a la extinción" $"$.

El derecho y los sistemas de justicia no están ajenos a tan inmensos desafíos.

Una de las áreas en las que más se menciona recientemente el uso de la IA en los sistemas de justicia es el de la elaboración de las sentencias y, como paso previo, la elaboración de demandas o contestaciones (actos de alegación).

Señala NIEVA-FENOLL ${ }^{62}$ que

"esta es probablemente la temática que puede dar más miedo a cualquier jurista, e incluso a cualquier ciudadano: que una maquina pueda dictar sentencias, de manera que nuestro destino esté en manos, no de personas como nosotros, sino de una aplicación que solo decide en función de aplastantes variables estadísticas y que, por ello, resolverá siempre de la misma forma, no solamente no adaptándose a los cambios, sino reafirmando sus "prejuicios" con el paso del tiempo y la acumulación de más decisiones en un determinado sentido, que serán sus propias decisiones".

Sin embargo, señala que no hay razón para inquietarse porque estamos lejísimos de ese panorama tenebroso y, además, irán surgiendo mecanismos para corregir la consolidación de las tendencias que precisarán de un modo u otro de la intervención humana.

\footnotetext{
${ }^{61}$ HARARI, Yuval, Ob. Cit., ps. 303 y 304.
}

${ }^{62}$ NIEVA-FENOLL, Jordi, Ob. cit., p. 99. 
Revista Eletrônica de Direito Processual - REDP.

Rio de Janeiro. Ano 13. Volume 20. Número 3. Setembro a Dezembro de 2019

Periódico Quadrimestral da Pós-Graduação Stricto Sensu em Direito Processual da UERJ

Patrono: José Carlos Barbosa Moreira (in mem.). ISSN 1982-7636. pp. 483-523

www.redp.uerj.br

Por su parte, señala HARARI ${ }^{63}$ :

"En el pasado eran muchas las cosas que solo los humanos podían hacer. Pero ahora robots y ordenadores nos están dando alcance, y puede que pronto nos avancen en la mayoría de las tareas. Cierto: los ordenadores funcionan de manera muy distinta a los humanos y parece improbable que se transformen pronto en algo próximo a lo humano. En particular, no parece que los ordenadores estén a punto de tener conciencia ni de empezar a experimentar emociones y sensaciones. A lo largo de las últimas décadas ha habido un avance inmenso en inteligencia informática, pero el avance en conciencia informática ha sido nulo. Hasta donde sabemos, en 2016 los ordenadores no son más conscientes que sus prototipos de la década de 1950. Sin embargo, estamos en el umbral de una revolución trascendental. Los humanos corren peligro de perder su valor porque la inteligencia se está desconectando de la conciencia".

Por, ende, mientras no se verifique ese hipotético salto, y como lo señala NIEVAFENOLL ${ }^{64}$, la IE puede ayudar en algunos aspectos de la elaboración de la resolución, pero no en todos ellos, no siempre y ni siquiera de manera completa, pero tampoco despreciable. Señala el autor ${ }^{65}$ que la inteligencia artificial no dicta sentencias, sino que solo ayuda a dictarlas y, por ende, las sentencias futuras quizá no estarán realmente mejor razonadas que ahora, pero sí que tendrán innegablemente mejores posibilidades de estarlo ${ }^{66}$. En realidad, depende de lo que el ser humano quiera aprovechar los recursos tecnológicos de que dispone.

Los abogados ya utilizan en algunos países -y podrían ser utilizados también por los jueces- simuladores de sentencias, y ya se habla incluso de simuladores que son abogados robots $^{67}$. Son herramientas que analizan los actos de proposición del proceso y los documentos

\footnotetext{
${ }^{63}$ HARARI, Yuval, Ob. Cit., p. 299.

${ }^{64}$ NIEVA-FENOLL, Jordi, Ob. cit., p. 16.

${ }^{65}$ NIEVA-FENOLL, Jordi, Ob. cit., p. 16.

${ }^{66}$ La máquina no tiene prácticamente límites de almacenamiento de información, a diferencia de los humanos.

${ }^{67}$ CHUQUICALLATA, en un artículo publicado recientemente refiere a un robot provisto de inteligencia artificial que podría poner en jaque a la comunidad jurídica. Señala que Ross es capaz de escuchar el lenguaje humano, rastrear más de 10 mil páginas por segundo y formular una respuesta mucho más rápido que cualquier abogado humano. Las respuestas de Ross incluyen citas legales, sugieren más artículos para estudiar e incluso calculan una tasa de confianza para ayudar a los abogados a preparar los casos. Además, por tratarse de una inteligencia artificial (IA), mientras más consultas recibe, más aprende, y su eficacia aumenta. Ross aprende de su interacción con humanos. Este software fue creado por una startup canadiense de la Universidad de Toronto. Los investigadores utilizaron la tecnología del superordenador Watson, desarrollado por la International Business Machines
} 
Revista Eletrônica de Direito Processual - REDP.

Rio de Janeiro. Ano 13. Volume 20. Número 3. Setembro a Dezembro de 2019

Periódico Quadrimestral da Pós-Graduação Stricto Sensu em Direito Processual da UERJ

Patrono: José Carlos Barbosa Moreira (in mem.). ISSN 1982-7636. pp. 483-523

www.redp.uerj.br

acompañados a los mismos, procesan los hechos expuestos en el contexto legal y jurisprudencial aplicable, y simulan cuál sería la decisión del juez. Estos sistemas son ofrecidos como un camino hacia una mayor previsibilidad y seguridad jurídica, pero, a la vez, nos colocan ante el desafío del "congelamiento" de las decisiones y la confirmación de los prejuicios de las sentencias anteriores.

En relación a los abogados y su trabajo, señala HARARI ${ }^{68}$ :

"dichos abogados no tienen por qué ser necesariamente humanos. Las películas y las series de televisión transmiten la impresión de que los abogados se pasan el día en tribunales gritando “¡Protesto!” y pronunciando apasionados alegatos. Pero la mayoría de los abogados corrientes pasan su tiempo revisando archivos interminables en busca de precedentes, resquicios legales y minúsculos fragmentos de pruebas potencialmente relevantes. Algunos están atareados intentando imaginar que ocurrió el día en que mataron a Pepito el de los Palotes o preparando un contrato comercial gigantesco que proteja a su cliente frente a cualquier eventualidad concebible. ¿Cuál será el destino de todos estos abogados cuando sofisticados algoritmos de búsqueda puedan localizar más precedentes en un día que un humano en toda su vida, y cuando los escaneos cerebrales puedan desvelar mentiras y engaños con solo pulsar un botón? Incluso a los abogados y los detectives con mucha experiencia les resulta difícil detectar engaños mediante la simple observación de expresiones faciales y del tono de voz. Sin embargo, mentir implica áreas cerebrales distintas de las que usamos cuando decimos la verdad. Todavía no llegamos ahí, pero es concebible que en un futuro no muy lejano los escáneres fMRI puedan funcionar como máquinas de la verdad casi infalibles. ¿Dónde dejará eso a millones de abogados, jueces, policías y detectives? Quizá necesiten volver a la universidad y aprender una nueva profesión".

Corporation (IBM), el mismo que en 2011 derrotó ampliamente a dos de los mejores participantes humanos del concurso de televisión Jeopardy. El computador inteligente Watson marcó, por esos años, el preludio de un definitivo e irreversible desarrollo de la IA. Gracias a sus algoritmos, Ross puede tener en cuenta la ideología del juez, las partes implicadas en el juicio y los tribunales de menor rango desde los que llegan las causas. Una vez que asimila la información, responde basándose en las leyes vigentes y traduciendo la terminología.

Se señala que en 2016, la firma estadounidense, Baker \& Hostetler, contrató a Ross para que formé parte del Departamento de Gestión de Quiebras, junto a un numeroso equipo de 50 abogados humanos. Según aseguran sus fundadores, la compañía decidió contratar a esa inteligencia artificial como abogado para formular hipótesis y fundamentarlas con citas de leyes o precedentes legales. (CHUQUICALLATA REATEGUI, Francisco, "Ross, el primer abogado robot que litiga usando inteligencia artificial" en https://legis.pe/ross-primer-abogado-robotlitiga-usando-inteligencia-artificial/).

${ }^{68}$ HARARI, Yuval, Ob. Cit., p. 344. 
Revista Eletrônica de Direito Processual - REDP.

Rio de Janeiro. Ano 13. Volume 20. Número 3. Setembro a Dezembro de 2019

Periódico Quadrimestral da Pós-Graduação Stricto Sensu em Direito Processual da UERJ

Patrono: José Carlos Barbosa Moreira (in mem.). ISSN 1982-7636. pp. 483-523

www.redp.uerj.br

Todavía lejos del panorama un tanto apocalíptico para la profesión jurídica que plantea el autor, en un ámbito de más generalización, es conocido que jueces y abogados pueden ya disponer de sistemas inteligentes de búsqueda de legislación y jurisprudencia que sin duda enriquece el proceso de elaboración de sus alegaciones y decisiones.

La aplicación de la IA de forma más intensiva implicará ahorro de tiempo y recursos.

Superados aspectos de costos de implantación es ya posible disponer de sistemas que permitan plantear demandas y defensas a través de una página web o de una aplicación.

El sistema de litigación on line se vuelve muy útil para los procesos monitorios, por ejemplo, pero también ha sido utilizado para otras estructuras y casos, como es el caso de Brasil $^{69}$.

Como señala VALIÑO $\operatorname{CES}^{70}$, en los últimos años se han impulsado, en el contexto de la Unión Europea ${ }^{71}$, no pocas iniciativas para contribuir a la difusión de las fórmulas de solución pacífica de conflictos, en particular, de aquéllas que favorecen la agilidad y la flexibilidad en la resolución de las controversias. Tomando como punto de partida la percepción de ineficacia que

${ }^{69}$ Ver de ARAÚJO SILVA, Paulo, “O Sistema PJe-Processso Judicial Electrônico”, Revista Sistemas Judiciales, Año 9, No 16, CEJA, ps. 64 y ss.

70 VALIÑO CES, Almudena, "Reflexiones en torno a la resolución en linea de conflictos surgidos en el ámbito del e-commerce", en Bueno de Mata, Federico (director) y otros, "Fodertics 7.0 - Estudios sobre Derecho Digital”, Universidad de Salamanca, España, 2019, ps.501 a 504.

${ }^{71}$ Señala VALIÑO CES que en la Unión Europea se trata de establecer un sistema europeo de resolución de litigios en línea- RLL, circunscrito al ámbito del consumo. Así, se previó el establecimiento de una plataforma de resolución de litigios en línea a escala de la Unión, a través del Reglamento de ejecución (UE) 2015/1051 de la Comisión, de 1 de julio de 2015, sobre las modalidades para el ejercicio de las funciones de la plataforma de resolución de litigios en línea, sobre modalidades del impreso electrónico de reclamación y sobre modalidades de cooperación entre los puntos de contacto previstos en el reglamento (UE) No 524/2013 del Parlamento Europeo y del Consejo sobre resolución de litigios en línea en materia de consumo . Esta plataforma RLL debe adoptar la forma de un sitio web interactivo y multilingüe que ofrezca un único punto de acceso a los consumidores y los comerciantes que quieran resolver extrajudicialmente litigios relativos a obligaciones contractuales derivadas de una transacción transfronteriza de comercio electrónico.

Asimismo, y desde una perspectiva española, señala la autora que la Ley 5/2012, de mediación en asuntos civiles y mercantiles y el RD 980/2013 que la complementa, ofrecen un marco legal básico de desarrollo y aplicación de mediaciones electrónicas. Junto a esta normativa, cabe destacar la Ley 7/2017, por la que se incorpora al ordenamiento jurídico español la Directiva 2013/11/UE del Parlamento Europeo y del Consejo, 21 de mayo de 2013, relativa a la resolución alternativa de litigios en materia de consumo. Señala la autora que la importancia de esta norma reside en su Disposición final séptima, toda vez que modifica la Ley 5/2012, suprimiendo su párrafo d) del apartado 2 del art. 2. De esta manera, ahora se puede aplicar esta Ley a la mediación en materia de consumo, lo que sin duda coadyuvará a resolver asuntos derivados de cualquier tipo de actividad comercial que se realice a través del Internet. Esta cuestión se considera plausible porque en la actualidad aumentan permanentemente las transacciones comerciales por esta vía y, por ende, también los conflictos surgidos a raíz de esta modalidad de hacer negocios (VALIÑO CES, Almudena, Ob. Cit., ps. 502 y 503). 
Revista Eletrônica de Direito Processual - REDP.

Rio de Janeiro. Ano 13. Volume 20. Número 3. Setembro a Dezembro de 2019

Periódico Quadrimestral da Pós-Graduação Stricto Sensu em Direito Processual da UERJ

Patrono: José Carlos Barbosa Moreira (in mem.). ISSN 1982-7636. pp. 483-523

www.redp.uerj.br

en ocasiones tiene el ciudadano respecto a la vía judicial y la idoneidad de las modalidades extrajudiciales para lograr una solución a sus conflictos, quizás se pueda ir más allá, posibilitando integrar en el Derecho a la Justicia una realidad social y profesional indiscutible como es la utilización de las nuevas tecnologías, en especial las Tecnologías de la Información y la Comunicación.

Así, como señala NIEVA-FENOLL ${ }^{72}$ la reclamación de una cantidad de dinero no discutida o un desahucio por falta de pago y la enorme mayoría de los procesos que se sustancian sin oposición, tienen un campo más que propicio para la IA. Si la prueba, además, es simplemente documental y los documentos son previsibles, la aplicación puede ser diseñada para analizarlos con resultados verdaderamente espectaculares, que ya se está demostrando que superan ampliamente las posibilidades de revisión humana.

Pero, en cualquier caso, los sistemas de justicia deberán estar atentos para que los prejuicios no sean el motor de la toma de decisiones y las probabilidades estadísticas no conduzcan a resolver los conflictos en perjuicio de los más vulnerables ${ }^{73}$.

\section{REFERENCIAS:}

\footnotetext{
${ }^{72}$ NIEVA-FENOLL, Jordi, Ob. cit., p. 25.

${ }^{73}$ Narra PASCUAL que la ingeniera informática estadounidense de origen ganés Joy BUOLAMWINI se dio cuenta un buen día cuando estudiaba en el MIT de que un robot en el que trabajaba no era capaz de reconocer su rostro. Meses después le pasó lo mismo con un robot social que probó durante una visita en Hong Kong. Cuando se ponía una máscara blanca, la cosa cambiaba. ¿Casualidad? Resulta que ambos sistemas habían usado el mismo software de reconocimiento facial basado en machine learning. "Si tu rostro se desvía demasiado de los patrones que le has dado al sistema para que aprenda, no te detectará, como me pasó a mí", cuenta en una charla TED colgada en Youtube que acumula más de un millón de visualizaciones. "Los algoritmos, como los virus, pueden propagar sesgos a escala masiva y a un ritmo acelerado", añade en la grabación. Este tipo de errores son demasiado comunes. Sin ir más lejos, Google etiquetó hace unos años a tres jóvenes negras como gorilas. La investigadora decidió tomar cartas en el asunto: fundó la Algorithmic Justice League para denunciar los sesgos de los algoritmos, servir de altavoz para que la gente exponga casos de abuso y desarrollar códigos de buenas prácticas en el diseño de estos sistemas. En Europa también tenemos organizaciones que monitorizan los algoritmos. Dos de las más importantes han sido fundadas por Lorena JAUME-PALASÍ. Filósofa de formación, a la mallorquina hace tiempo que le interesa la dimensión ética de la automatización y la digitalización. Es cofundadora de AlgorithmWatch, una organización afincada en Berlín (donde reside) que analiza la ética de los procesos algorítmicos. Recientemente abandonó la ONG y ha fundado otra, The Ethical Tech Society, que se centra más en la relevancia social de los sistemas automáticos. "La conversación que tenemos desde hace años sobre los sistemas algorítmicos está basada más en el miedo que en riesgos reales. Hacía falta crear una ONG que lanzase posiciones normativas fundadas en hechos", explica (PASCUAL, Manuel G, Ob. cit.).
} 
Revista Eletrônica de Direito Processual - REDP.

Rio de Janeiro. Ano 13. Volume 20. Número 3. Setembro a Dezembro de 2019

Periódico Quadrimestral da Pós-Graduação Stricto Sensu em Direito Processual da UERJ

Patrono: José Carlos Barbosa Moreira (in mem.). ISSN 1982-7636. pp. 483-523

www.redp.uerj.br

ARAÚJO SILVA, Paulo, “O Sistema PJe - Processso Judicial Electrônico”, Revista Sistemas Judiciales, Año 9, $\mathrm{N}^{\circ}$ 16, CEJA, ps. 64 y ss.

ARELLANO, Jaime, "Presentación”, en BINDER, Alberto y GONZÁLEZ, Leonel (Directores)

y otros,"Gobierno Judicial. Independencia y fortalecimiento del Poder Judicial en América Latina", CEJA, Santiago de Chile, p 7.

BINDER, Alberto, "Gobierno judicial. Independencia y fortalecimiento de los jueces", en BINDER, Alberto y GONZÁLEZ, Leonel (Directores) y otros, Ob. Cit., p 16.

CEJA, "10 Ideas sobre el modelo de reforma a la justicia civil que promueve CEJA en América Latina el Caribe”. http://www.cejamericas.org/Documentos/2018/10_Ideassobreelmodelodereformaalajusti ciacivilquepromueveCEJAenAmericaLatinayelCaribe_coninfografias.pdf

CHUQUICALLATA REATEGUI, Francisco, "Ross, el primer abogado robot que litiga usando inteligencia artificial" en https://legis.pe/ross-primer-abogado-robot-litigausando-inteligencia-artificial/

ESPERANZA Silvia (coordinadora) y otros, "Derecho Procesal Civil y Comercial - Estudios en homenaje al Dr. Jorge W. Peyrano", Rubinzal-Culzoni Editores, Buenos Aires, 2018, ps.749 y ss.

FANDIÑO, M., "Lineamientos para la transformación de los juzgados civiles en base a los nuevos paradigmas procesales" en "La gestión judicial de los nuevos tribunales civiles", CEJA, 2018.

GARCÍA, R. "Develación, Diagnóstico y Proyecciones del judicial case management en Chile, desde la perspectiva del derecho comparado”, 2018, Tesis. Pontificia Universidad Católica de Valparaíso.

HARARI, Yuval, "Homo Deus - Breve historia del mañana", Debate, Montevideo, 2018.

LILLO, Ricardo, "Indicadores de CEJA: El rol de las TIC en una justicia para ciudadanos", Revista Sistema Judiciales, CEJA. Año 9, № 16.

LUENGO-OROZ, Miguel, "La inteligencia artificial tiene una deuda contigo" en https://retina.elpais.com/retina/2019/01/04/tendencias/1546604928_551805.html 
Revista Eletrônica de Direito Processual - REDP.

Rio de Janeiro. Ano 13. Volume 20. Número 3. Setembro a Dezembro de 2019

Periódico Quadrimestral da Pós-Graduação Stricto Sensu em Direito Processual da UERJ

Patrono: José Carlos Barbosa Moreira (in mem.). ISSN 1982-7636. pp. 483-523

www.redp.uerj.br

MARCET, Juan Pablo, "El gobierno del sistema judicial en Argentina: un enfoque organizacional”, en Estudios sobre la Administración de Justicia No 2, Fores, Buenos Aires 2004.

MARINONI, L.; ARENHART, S., MITIDIERO, D., "Novo Código de Processo Civil comentado”, Thomson Reuters-Revista dos Tribunais, Brasil, 2016.

NIEVA-FENOLL, Jordi, "Inteligencia artificial y proceso judicial”, Marcial Pons, Madid, 2018.

OTEIZA, Eduardo, “Reformas procesales en América Latina. Tendencias y tensiones entre los Estados Nación y la Comunidad Internacional” en OTEIZA, Eduardo (coordinador) y otros, "Sendas de la reforma de la justicia a principios del siglo XXI", Marcial Pons, Madrid, 2018, ps. 49 y 50.

PEREIRA CAMPOS, Santiago; VILLADIEGO, Carolina y CHAYER, Héctor, “Bases Generales para una Reforma a la Justicia Civile en América Latina y el Caribe”, publicado en PEREIRA CAMPOS, S. (Coordinador) y otros, "Modernización de la Justicia Civil”, Universidad de Montevideo, 2011.

PICHÉ, C. Y NOREAU, P. "Reformas a la Justicia Civil en Quebec y Canadá". Centro de Estudios de Justicia de las Américas, 2018, citado por FANDIÑO, M., Ob cit., ps 31 y ss.

VALIÑO CES, Almudena, "Reflexiones en torno a la resolución en linea de conflictos surgidos en el ámbito del e-commerce", en Bueno de Mata, Federico (director) y otros, "Fodertics 7.0 - Estudios sobre Derecho Digital”, Universidad de Salamanca, España, 2019, ps.501 a 504 .

VARGAS VIANCOS, Juan Enrique, “Curso sobre instrumentos para la implementación de un sistema acusatorio oral - Herramientas para el diseño de Despachos Judiciales”, Viña del Mar, 2006, Disponible en: www.cejamericas.org 